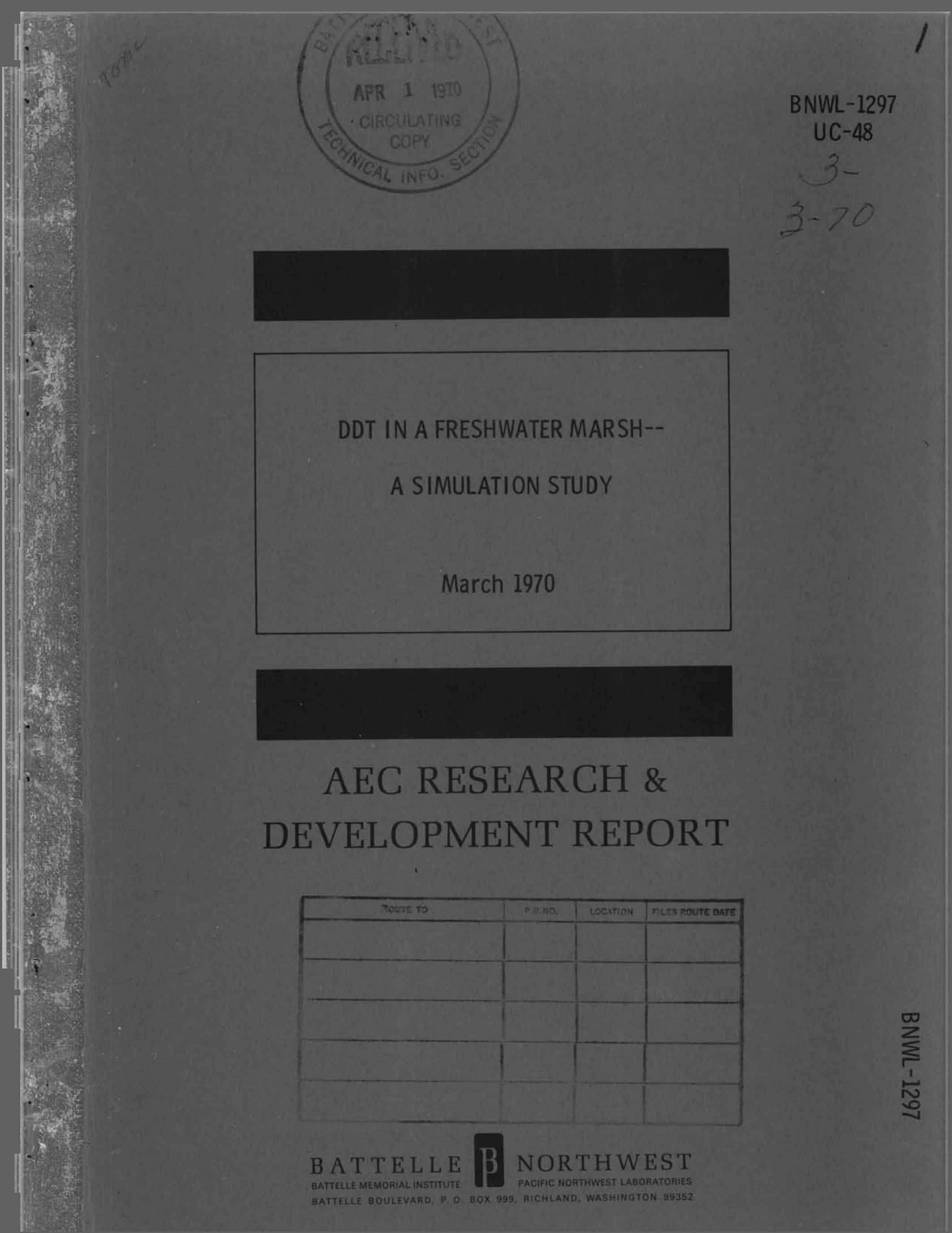




\section{LEGAL. NOTICE}

This report was prepared as an account of Government sponsored work. Neither the United States, nor the Commission, nor any person acting on behalf of the Commission:

A. Makes any warranfy or representation, expressed or implied, with respect to the accuracy, completeness, or usefulness of the information contained in this report, or that the use of any information, opparatus, method, or process disclosed in this repart moy not infringe privately owned rights; or.

B. Assumes any liabilities with respect to the use of, or for domages resulting from the use of any information, apporatus, method, or process disclosed in this report.

As used in the above, "person acting on behalf of the Commission" includes any employee or contractor of the Commission, or employee of such contractor, to the extent that such employee or contractar of the Commission, or employee of such contractor prepares, disseminates, or provides access to, ony information pursuant to his employment or controct with the Commission, or his employment with such contractor.

PACIFIC NORTHWEST LABORATORY

RICHLAND, WASHINGTON

oparated by

BATTELLE MEMORIAL INSTITUTE

for the

UNITED STATES ATOMIC ENERGY COMMISSION UNDER CONTRACT AT(45-1)-1830 
BNWL-1297

UC-48, Biology and Medicine

DDT IN A FRESHWATER MARSHA SIMULATION STUDY

by

L. L. Eberhardt, R. L. Meeks, and T. J. Peterle

Ecosystems Department; Winous Point Shooting Club, Port Clinton, Ohio; The Ohio State University, Columbus, Ohio.

March 1970

79

BATTEUE MEMORIAL INSTITUTE

PACIFIC NORIHMEST LABORATORIES

RICHIAND, WASHNGTON 99352 


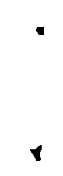

Printed in the United States of America Available from

Clearinghouse for Federal Scientific and Technical Information National Bureau of Standards, U.S. Department of Commerce Springfield, Virginia 22151

Price: Printed Copy $\$ 3.00 ;$ Microfiche $\$ 0.65$ 


\section{DDT IN A FRESHWATER MARSH--A SIMULATION STUDY*}

\section{$\underline{\text { ABSTRACT }}$}

A computer simulation model has been constructed to represent the dynamics of chlorine-36 labelled DDT in a Lake Erie marsh. An exponentially decreasing input function (representing release of DDT from the granular formulation in which it was applied) determines concentration in water, from which one- or two-compartment models represent the concentration in various forms of flora and fauna. Observational data on 10 plant species, 6 invertebrates, and 3 vertebrate species were modelled, Five species (a plant, an invertebrate species, and the 3 vertebrates) were used for a food-chain simulation, The overall results generally suggest that simple models, of the kind used to study radionuclide transfer through food chains, will provide reasonably good representations of the behavior of DD in food chains. It is suggested that controlled experiments are needed to properly identify the components of a model, and that a number of questions about sampling methodology remain unanswered.

\footnotetext{
"This paper is based on work performed under United States Atomic Energy Commission Contract AT(45-1)-1830.
} 


\section{INTRODUCTION}

This study has two purposes, One is to investigate the applicability of methods used for modelling radionuclide transfers through food chains to studies of pesticide problems, and the second is to suggest some essential aspects for further study. Neither purpose can be fully served by the data at hand, but the urgency of pesticide problems is such that even partial success can be of considerable use in planning further research. Much has been written about the importance of "food chain" phenomena in the distribution and coneentratfon of pesticides, but very few efforts have been made to actually model a single set of data. A major difficulty has been the very considerable costs involved in analyzing enough samples for a food chain study, The data examined here were obtained through the use of radioactive chlorine-36 on the phenyl ring of DDT. Because the phenyl ring chlorine atoms remain attached to all known DDT metabolites, it was possible to analyze many environmental samples for DD and its degradation products by beta-counting for the chlorine-36 tag. Results of the study have been published (Meeks, 1968, and Meeks and Peterle, 1967) in detail, so that only essential features need be repeated here.

The labelled DDT was dissolved in xylene, combined with the emulsifier Triton B-1956, and then mixed with inert attapulgite granules. On July 7, 1964, the treated granules were applied by helicopter to an enclosed four-acre marsh along the southwestern edge of Lake Erie at a rate of 0.2 pounds of technical DDT on 100 pounds of granules per acre-foot of water. An intensive sampling program was continued over 15 months, and further samples have been taken from the area up to \%hepresent time. 
Major emphasis in this analysis is on the first 3 months of the study. Our efforts at simulation have been directed more towards exploring the data than to the construction of a detailed model. We have thus used difference and differential equations interchangeably, as convenient, and have not attempted to study variability in depth, nor incorporate any stochastic elements in the model.

The programs used were written in the DYNAMO language (Pugh, 1963) and run on an IBM 7090 computer. The basic models are very much the same as those used to study food-chain behavior of cesium-137 in a lichencaribou-Eskimo system, so that further details of the simulation procedure are available in an account of that study (Eberhardt and Hanson, 1969). The basic unit is a difference equation corresponding to the differential equation:

$$
\frac{d y}{d t}=\lambda(t)-\mu y
$$

where y represents the concentration of DDT in an element of the system (conveniently expressed in parts per billion to correspond with levels in water), $\lambda(t)$ is an input function (usually concentration in another "compartment"), and $\mu$ is a loss or excretion rate. The time unit ( $\Delta t$ ) has been taken as one hour throughout the study. Results were checked against computations in which the actual solutions to corresponding differential equations were used, and some examples are discussed later in the paper. Since the equations are simple and data points (over time) few in number, a good deal of exploration and computation of rateconstants was done on a "desk-size" computer (Mathatron 4280T), 
In retrospect, much of the computational effort in the study seems to have gone into wandering down blind alleys and backing up. It is hoped that one of the benefits of the study may be that of suggesting ways to quickly construct a rough deterministic model for a set of data whf ch can serve as a guide for an on-going study, Clearly, a timesharing computer terminal would be an optimal tool for that purpose.

For the most part, the modelling done here can best be described as mimicry, This is because we do no\% have the results of experiments specifically designed to test the applicability of an assumed mechanism to the phenomenon observed, We thus proceed wrth the simplest model that seems to fit \%hedata, and depend on subjective appraisal of plotted data points for reassurance that the functional form used is at least admissable--but virtually never confirmable from the data at hand, Since the simple compartment models do appear adequate, it would seem that the logical future procedure is to do both careful statistical tests on new data and to perform experiments to confirm \%heexistence of supposed compartments.

The balance of this report describes the procedures used for the several major components of the marsh system, Results are given in an extensive set of figures, in the hope that readers may note features we have overlooked, he also present the outcome of several ways of estimating rate constants as a demonstration sf the differences that ensue from using different methods, 


\section{DDT I N WATER}

Direct data on the rate of release from the granules are not available. Initial modelling efforts based on either a constant. rate of release, or a rate increasing linearly with time (both cut off at 12 or 24 hours) were not compatible with the observed values. We then arbitrarily assumed that release started at a level, $\lambda$, and declined exponentially, giving an input function representing release of DDT from granules as:

$$
\lambda(t)=\lambda e^{-k t}
$$

so that the solution of equation (I) becomes:

$$
y=\frac{\lambda}{k-\mu}\left[e^{-\mu t}-e^{-k t}\right]
$$

with $\mathrm{k}>\mu$ and $\mathrm{y}(0)=0$.

We thus assume DD to be removed from the water at a constant fractional rate $(\mu)$. While it is evident that concentrations in the water declined rapidy, we do not have data to show quantitatively the fate of DDT suspended in water. Rather than make arbitrary assignments, we have simply assumed that DD was removed at a constant rate, and that transfers to the biota were proportional to current concentrations in water.

A further difficulty is introduced by the presence of appreciable amounts of suspended materials (chiefly phytoplankton). These were assayed for DDT on the basis of material collected on a 0.45 micron filter from $50 \mathrm{ml}$ of water (results were calculated in ppb on the basis of the volume of water filtered). The remaining $750 \mathrm{mI}$ of an $800 \mathrm{ml}$ 
sample was extracted with a solvent, and the extracts analyzed for DDT. Presumably most of the DDT taken up by the biota came initially from the water. We are thus faced with the problem of estimating levels in water, and it seems that such estimates should pertain to water free of suspended matter. It may also be assumed, of course, that some of the DDT was transferred from suspended material, and this point will be returned to later, For the present, we estimate quantities in filtered water simply by subtracting, giving the following data:

ppb DDT in:

\begin{tabular}{cccc}
$\begin{array}{c}\text { Time } \\
\text { (hours) }\end{array}$ & $\begin{array}{c}\text { Unfiltered } \\
\text { Water }\end{array}$ & $\begin{array}{c}\text { Suspended } \\
\text { Materials }\end{array}$ & $\begin{array}{c}\text { Filtered Water } \\
\text { (by subtraction) }\end{array}$ \\
\cline { 2 - 3 } 1 & 3.0 & 0.6 & 2.4 \\
4 & N.D. & N.D. & $0 ?$ \\
6 & 0.3 & N.D. & 0.3 \\
8 & 0.9 & N.D & 0.9 \\
12 & 1.4 & 0.2 & 1.2 \\
24 & 1.4 & 0.8 & .6 \\
48 & 1.7 & 0.4 & 1.3 \\
120 & 1.8 & 1.5 & .3 \\
168 & 0.4 & N.D. & .4 \\
336 & 0.7 & N.D. & .7 \\
720 & N.D. & N.D. & $0 ?$
\end{tabular}

The initial surface concentration at $\mathbf{1}$ hour has been neglected in modelling, since it apparently was due to a transient surface situation 
(probably a xylene-granule-dust film) as appreciable amounts of DDT were not encountered in most of the biota when first assayed 4 hours post-application. Water samples were taken fromthe surface, but most of the release was from granules on the bottom (average depth about 1 foot). Very likely a lag-term for transport from bottom to surface should be used, but our knowledge of the release mechanism is not adequate for the purpose. Beyond this transient component, detectable concentrations in surface water first appeared between 4 and 6 hours post-application.

The small size of the samples for suspended material casts some doubt on our procedural treatment of "non-detectable" (N.D. above) as equivalent to no DDT content. Furthermore, although water samples were handled expeditiously, there were some prospects of losses to container walls, and so on. Thus, we have arbitrarily disregarded the estimates of levels in filtered water at 24 and 336 hours. The value at 24 hours seems unrealistically low (and might well be a consequence of an overestimate for level on suspended matter), while that at two weeks (336 hours) seems unreasonably high, Since levels in the water "drive" the rest of the system, an error at this point will evidently be propagated throughout the study. Consequently the matter of neglecting the "high" observation at 336 hours is important, but we found little reason to believe that any important return of DD from the biota could have occurred at this time. A more likely, but completely unknown, alternative is some phenomenon that caused a sudden release of DDT in bottom sediments-but we rather doubt any such event occurred.

Returning to equation 3 , a crude estimate of $\mu$ can be formed from the data-points at 48,120 , and 168 hours. These suggest $\mu$ to be on 
the order of .01 to .02 (proportion of DDT lost from filtered water per hour). We initially assumed $\mu=.01$, and contrasted the outcome of various arbitrary choices of $\mathrm{k}$ and $\lambda$ with the observations. That is, equation (3) can be rearranged to:

$$
y / \lambda=\frac{1}{k-\mu}\left[e^{-\mu t}-e^{-k t}\right]
$$

Inserting observed values for y permits one to compute 4 values of $\lambda(t=8,12,48$, and $168 \mathrm{hrs})$ for any arbitrary choice of k. Selecting $k=.10$ yielded values of $\lambda$ on the order of .18 to .19. A good deal of simulation with $\mathrm{A}=.20$ indicated that a lower value might give better agreement of data and simulation, so we fixed $\lambda$ as equal to 0.17. While these values $(\lambda=0.17, \mathrm{k}=0.10, \mu=0.01)$ gave results which seem compatible with the data, a somewhat less subjective means of estimation might be preferred. We thus turned to non-linear least-squares calculations.

Since many of the computer routines for doing non-linear leastsquares fits may "hang-up" on data of this sort (small and variable samples), we elected to try a direct search on the small computer (Mathatron), starting with the above set of values, and calculating the sum-of-squareddeviations (on 7 data-pairs) for an arbitrarily sampled range of values $(.10 \leq \lambda \leq .20,0.4 \leq \mathrm{k} \leq .14, .004 \leq \mu \leq .024)$. For fixed values of A, this process found 6 "local" minima in about 8 hours of computing. Since there was a fairly wide range of possible values, but not much difference in sum-of-squares at (or near) the minima, we anticipated some difficulty with automated schemes (but later trials of several 
programs yielded nearly the same parameter estimates). The various minima found were as follows:

$\begin{array}{cccc}\lambda & \mathrm{k} & \mu & \begin{array}{c}\text { Sum of } \\ .10\end{array} \\ .12 & .04 & .018 & .306 \\ .12 & .04 & .022 & .229 \\ .14 & .06 & .014 & .251 \\ .16 & .06 & .016 & .217 \\ .17 & .08 & .014 & .255 \\ .08 & .014 & .285\end{array}$

For comparison, the sm of squared deviations at our initial set of constants was .301 . Rather less searching was done at values of $\lambda$ above .17, but there appeared. to be a minimum in the neighborhood of $\lambda=.20$, $k=.14$, and $\mu=.008$. Examination of the individual deviations showed some $2 / 3$ or more of the variability was associated with the first observation (at 6 hours). Dropping that observation reduced the minimum sum of squared deviations to about .06 at $\lambda=.17, \mathrm{k}=.08, \mu=.014$. A comparison of observed and expected values is: 
ppb DDT

\begin{tabular}{ccc} 
Time (hours) & Observed & Expected \\
\hline 6 & .3 & .77 \\
8 & .9 & .95 \\
12 & 1.2 & 1.19 \\
48 & 1.3 & 1.26 \\
120 & .3 & .48 \\
168 & .4 & .24 \\
720 & 0.0 & 0.00
\end{tabular}

In view of the fact that we had previously arbitrarily dropped two observations, efforts to explain a further discrepancy are of somewhat dubious value. But one of our major purposes here is to point out things to look for in future studies, so it is worth noting that application of the granules was completed about 8 a.m., and events represented by the 6 and 8 hour observations thus transpired between roughly 2 and 4 p.m. of a July day, One might suppose that any time lag associated with diffusion of DDT from the marsh bottom might be at least reduced, and possibly nearly eliminated as the water began to heat up.

Further speculation might take the direction of noting that the last 3 points (120, 168, and 336 hrs) suggest an increasing trend, an argument we can only refer to in terms of observations on levels in the biota, which do not suggest such a second peak to be realistic.

Modelling concentrations in suspended material is considerably hampered by the high level ( 5 ppb) at 120 hours being followed by "nondetectable" levels at 168 and 336 hours. The 120-hour value may simply 
be too high (there was a sizable standard error, 0.5 for 4 observations), Since we again do not know the ultimate fate of DDT on the suspended matter, and in view of the anomalous-looking data points, we have more or less set this component aside for future reference. It was arbitrarily assumed that uptake and retention could be represented by:

$$
\frac{d y_{2}}{d t}=c_{1} y_{1}-\mu_{2} y_{2}
$$

where $y_{1}$ represents concentration in the water. The loss rate $\left(\mu_{2}\right)$ was set at the rate initially used for water (.01) and the "transfer coefficient" $\left(c_{1}\right)$ was selected mostly on the basis of outcome--a computed curve which passes "near" the available data points having values other than "non-detectable." It may well be possible to produce a curve which drops to low levels at 168 hours--but probably only by the dubious seeming practice of so-to-speak disconnecting suspended matter from its assumed source of DDT (water), or by assuming that such material is rapidly removed from suspension, as would perhaps have happened if the living components of the suspended materials suddenly died. However, since we have no data on plankton populations, it seems best to suspend judgment on this point until specific experiments are conducted.

Results of the simulation for water and suspended material are compared with the data points in Figs. 2 to 4 , while Fig. 1 shows the course of the assumed release of DD from the granules (the Figures are appended to this report). As has been previously noted, two of the points in Fig. 2(DDT in filtered water) were disregarded in the analysis as being completely out of line with the model, and the first observation 
was not used in the final least-squares fitting. Figure 4 was constructed by simply adding the computed concentrations in water and suspended material. An immediate conclusion from the analysis thus far is that the status of DDT on suspended matter is a weak point in the data. Preparation efficiency was excellent for suspended materials but nothing is known about the composition (silt, detritus, plankton) or probable component variation from day to day of the study. As Meeks (1968:380) has pointed out, a filtering system that would handle more than the $50 \mathrm{ml}$ actually used might have improved matters considerably, and might also have permitted determination of the actual weights of suspended material, with better data, a more realistic model might have been constructed for the DDT content of suspended matter. It appears likely that a large fraction of the DDT in water was actually transferred to the suspended material, whereas we have assumed concentrations there to constitute a "compartment" with inputs proportional to current levels in water. An important unknown is the ultimate fate of DDT on suspended material--how much was transferred to other elements of the biota, and how much wound up in bottom sediments? Some fraction might also have been released back to the water, too. In the absence of such information, we have resorted to using the curve of Fig, 2 (DDT in filtered water) as the input to the other elements of the system.

\section{DDT I N PLANIS}

Meeks (1968) reported DDT measurements on 16 plant species. We have simulated concentrations for 10 species. Four of the remaining 6 were eliminated in consequence of insufficient data, and 2 species 
(cattail and muskgrass) exhibited patterns of DDT levels which precluded estimating rate constants. Only Cladophora and duckweed (see Meeks, 1968: 382 for scientific names) were sampled as entire plants, while the others were represented by either the top $10 \mathrm{~cm}$ or base of new shoots, depending on the nature of the plant.

Plots of plant concentrations of DD against time suggest that at least two phenomena were involved, an immediate rise to the maximum concentration which quickly declined, followed by a long, gradual further decrease throughout the 3 months of the initial sampling period (sampling was not resumed until the following April, 9 months after application). Thus, we assumed a two-compartment model as the minimal scheme for simulation. Presumably the first, or "fast" compartment is a transient affair, reflecting levels of DDT in the water, while the second or "slow" compartment includes DDT variously bound to plant tissues. We do not have data on the actual mechanics or mechanisms of these so-called compartments, and an obvious refinement in another such study would lie in the use of autoradiography of plant sections, along with dissection of specific tissues for separate analysis. With present knowledge, using more than two compartments seems ruled out by the impracticality of making any sort of objective determination of rate constants, As it stands now, our best data pertain to the "slow" compartment which is presumably the important one, anyhow. It is this compartment which contains virtually all of the DDT after the first two weeks post-application.

Some readers may object to our rather glib assumption of compartments and the simple mechanisms of uptake and retention used. Our argument is gust that the intention of the study is to see how well a very 
simple-minded model represents the data, mostly in the hope that some degree of success will encourage further study, both experimentally and by analysis of other, similar data. It may also be remarked that many workers in diverse fields use compartment models as convenient abstractions of complex biological systems.

After various false starts, we settled on the assumption that negligible quantities of DDT remained in the "fast" (hereafter, first) compartment after DD was apparently reduced to low levels in water at about 14 days post-application, It was further assumed that a constant rate of loss from the second ("slow") compartment prevailed after 14 days. Thus, we could use the data points at and beyond 14 days (336 hours) for regression estimates of the loss rates, giving a maximum of 4 points (2 weeks, 1, 2, and 3 months post-application). As is often the case, we started out by approximating the slopes with a ruler and semi-logarithmic plots of data, and came ultimately to more objective methods as it began to seem that modelling was indeed feasible. Readers who have occasion to estimate such constants from variable data may be interested in comparing estimates from the three methods ultimately used (Table 1). The first method constituted, as noted above, "eye-fitting" on semilogarithmic paper, while the second depended on performing linear regression calculations on logarithms of DDT concentrations against time (in hours). The third method depended on non-linear least-squares estimates from untransformed data, initially computed by manual, iteritive solution of the normal equations on the small computer, and later checked by a standard program (Gaussian convergence) used on a Univac 1108 computer. 
TABLE

Estimates of Loss Rates for Plants, Using Three Methods

\begin{tabular}{|c|c|c|c|c|c|c|}
\hline Plant & $\begin{array}{c}\text { Number of } \\
\text { Data Points }\end{array}$ & "Graphic" & Log-linear & $\underline{s}^{2}$ & $\begin{array}{l}\text { Non-linear } \\
\text { Least Squares } \\
\end{array}$ & $\underline{s}^{2}$ \\
\hline Sago pondweed & 4 & .00017 & .00016 & .018 & .00018 & .008 \\
\hline Curly-leaf pondweed & 4 & .00069 & (positive slope) & -- & .00009 & $N 4$ \\
\hline Narrow-leaf pondweed & 2 & .00250 & \multicolumn{4}{|c|}{ (2 observations) } \\
\hline Water milfoil & 4 & .00088 & .00066 & .895 & .00078 & .858 \\
\hline Bur reed & 4 & .00050 & .00048 & .004 & .00057 & .004 \\
\hline Soft-stem bulrush & 3 & .00180 & .00165 & .054 & .00392 & .008 \\
\hline Duckweed & 4 & .00110 & .00077 & .172 & .00554 & .076 \\
\hline Coontail & 3 & .00120 & .00117 & .042 & .00151 & .023 \\
\hline Cladophora & 4 & .00160 & .00115 & 2.83 & .00588 & .111 \\
\hline Bladderwort & 4 & .00110 & .00124 & .004 & .00115 & .001 \\
\hline Cat-tail & 4 & -- & .00078 & .058 & .00407 & .030 \\
\hline
\end{tabular}


Estimates of the variance about regression were calculated from the mean-squared-deviations of untransformed data from the fitted lines.

This obviously favors the non-linear least-squares method, since the parameter estimates are those which minimize the squared deviations. The outcome of the comparison of methods suggests "eyeball" estimates may serve as starting points, but that non-linear least-squares estimates may, on occasion, differ appreciably from those obtained by log-linear regression methods.

Selection of the "best" estimates depends on the frequency distribution of residuals about regression, a matter both beyond the scope of the data and this paper, where the uncertain framework of our models precludes much reassurance from statistical analyses. It does seem worthwhile, however, to attach standard errors to the loss-rate estimates. These values suggest (Table 2) that there are, in fact, real differences among the rates, as is further demonstrated by comparing data points to calculated curves (see below).

To estimate uptake rates, we note that the model for a given plant compartment is identical to equation (5), with solution:

$$
y_{i}=\frac{c_{i}^{\lambda}}{k-\mu}\left[\frac{e^{-\mu t}-e^{-\gamma_{i} t}}{\gamma_{i}-\mu}+\frac{e^{-k t}-e^{-\gamma_{i t}}}{k-\gamma_{i}}\right]
$$

where $c_{\mathbf{i}}$ represents a "transfer" rate (from water) and $y_{\mathbf{1}}$ the rate of loss from the compartment $(\mathrm{A}, \mathrm{k}$, and $\mu$ are the parameters relevant to DDT dynamics in water, and have been estimated above). Using observed levels at 14 days (336 hours) for $y_{i}$, only $c_{i}$ remains unknown, and can 
TABLE 2

Loss Rate Estimates and Standard Errors

\section{$\underline{\text { Plants }}$}

Sago pondweed

Curly-leaf pondweed

Narrow-leaf pondweed

Water milfoil

Bur reed

Soft-stem bulrush

Duckweed

Coontail

Cladophora

Bladderwort

Cat-tail
N
4
4
2
4
4
3
4
3
4
4
4

Loss Rate

$1.8 \times 10^{-4}$

$25.0 \quad "$

$7.8 \quad "$

$5.7 \quad "$

$39.2 \quad 1 "$

$55.4 \quad "$

$15.1 \quad "$

$58.8 \quad "$

$11.5 \quad 11$

$40.7 \quad "$ $\underline{\text { Standard Error }}$

$0.95 \times 10^{-4}$
4.6

$4.8^{--} \times 10^{-4}$

$1.8 \quad " 1$

$14.5 \quad " 1$

35.0

$4.2 \quad "$

$17.8 \quad "$

$0.52 \quad "$

31.0

\section{$\underline{\text { Animals }}$}

Red leech

Crayfish

Crayfish*

Dragonfly naiad

Backswimmer

Bloodworm

Ramshorn snail

Carp

Carp*

Bullhead

Bullheadn

Green sunfish

Green sunfish*

$\begin{array}{rrr}2 & 16.3 \times 10^{-4} \\ 4 & 8.4 & " 1 \\ 5 & 12.8 & " 1 \\ 3 & 7.6 & " \\ 4 & 28.4 & " \\ 3 & 16.8 & " \\ 3 & 32.4 & " 1 \\ 2 & 13.7 & " 1 \\ 7 & 7.8 & " 1 \\ 2 & 7.4 & " \\ 7 & 5.9 & " \\ 3 & 2.9 & " \\ 5 & 5.9 & \end{array}$

$3.4^{--} \times 10^{-4}$
$2.4 \quad " 1$
$6.9 \quad " 1$
$4.1 \quad "$
$1.8 \quad "$
$20.6 \quad "$
$3.0 \times 10^{-4}$
$2.0 \times 10^{-4}$
$3.9 \quad " 1$
$1.9 \quad "$

"Determined in "clean water" (see below).

thus be roughly estimated. Results are summarized in Table 4 along with parameters for the first compartment, and for invertebrates.

The transient nature of levels in the first compartment makes it difficult to provide more than a gesture at estimating rate constants. We proceeded by first calculating levels in the second compartment up to 720 hours, and subtracting these from the observed values (Table 3 ). 
The differences (representing quantities in the first compartment) suggest that some plants had peak levels in the neighborhood of 24 hours postapplication, while others peaked appreciably later (mostly around 72 hours). Since there did not seem to be much prospect for useful estimates of first-compartment loss rates from the data, we ran a sequence of simulations with a fixed transfer rate (immaterial to the point at issue) and incrementally increasing loss rates. These suggested that a loss rate of 0.20 would yield a peak at roughly 24 hours, whf le a rate of 0.02 would peak around 72 hours. Consequently, we assignedthese two rates to the 'corresponding plants, and turned to transfer rates.

TABLE 3

Observed Levels of DDT and Computed Values for Second Compartment (ppb)

\begin{tabular}{|c|c|c|c|c|c|c|}
\hline \multirow[b]{3}{*}{ Time } & \multicolumn{3}{|c|}{ Sago pondweed } & \multicolumn{3}{|c|}{ Curly-leaf pondweed } \\
\hline & Observed & \multicolumn{2}{|c|}{ Long-term } & \multirow[b]{2}{*}{$\alpha$} & \multirow[b]{2}{*}{$C$} & \multirow[b]{2}{*}{ D } \\
\hline & Level & Compartment & Difference & & & \\
\hline 4 & 140 & 10 & 130 & & & \\
\hline 8 & 1860 & 40 & 1820 & & & \\
\hline 24 & 2140 & 230 & 1910 & 1190 & 180 & 1010 \\
\hline 72 & 2050 & 790 & 1260 & 2160 & 640 & 1520 \\
\hline 168 & 1100 & 1240 & - & 1080 & 1010 & 70 \\
\hline 336 & 1300 & 1350 & - & 1070 & 1110 & -- \\
\hline 720 & 1070 & 1280 & -- & 290 & 1090 & -- \\
\hline 1440 & 880 & 1120 & & 490 & 1020 & \\
\hline \multirow[t]{2}{*}{2160} & 980 & 990 & & 800 & 960 & \\
\hline & \multicolumn{3}{|c|}{ Narrow-leaf pondweed } & \multicolumn{3}{|c|}{ Water Milfoil } \\
\hline \multicolumn{7}{|l|}{4} \\
\hline 8 & & & & & & \\
\hline 24 & 6460 & 190 & 6270 & 1690 & 200 & 1490 \\
\hline 72 & 2810 & 600 & 2210 & 1370 & 680 & 690 \\
\hline 168 & 730 & 810 & -- & 2070 & 1030 & 1040 \\
\hline 336 & 600 & 620 & - & 980 & 1020 & -- \\
\hline 720 & 230 & 240 & - & 940 & 770 & -- \\
\hline 1440 & & & & 130 & 440 & \\
\hline 2160 & & & & 460 & 250 & \\
\hline
\end{tabular}


Bur reed

\begin{tabular}{|c|c|c|c|c|c|c|}
\hline \multirow[b]{3}{*}{ Time } & \multicolumn{3}{|c|}{ Bur reed } & \multicolumn{3}{|c|}{ Soft-stem bulrush } \\
\hline & Observed & Long-term & & & & \\
\hline & Level & Compartment & Difference & O. & C. & D. \\
\hline 4 & & & & 240 & 10 & 230 \\
\hline 8 & & & & 260 & 50 & 210 \\
\hline 24 & 1080 & 90 & 990 & 950 & 320 & 630 \\
\hline 72 & 3060 & 300 & 2760 & 3160 & 1000 & 2160 \\
\hline 168 & 780 & 460 & 320 & 990 & 1220 & -- \\
\hline 336 & 450 & 470 & - & 740 & 770 & -- \\
\hline 720 & 360 & 380 & -- & 150 & 180 & -- \\
\hline 1440 & 170 & 250 & & 100 & 10 & \\
\hline \multirow[t]{2}{*}{2160} & 210 & 170 & & & & \\
\hline & & Duckweed & & \multicolumn{3}{|c|}{ Coonta i 1} \\
\hline 4 & $(17,670)$ & 40 & & 40 & 10 & 30 \\
\hline 8 & 780 & 180 & 600 & 2040 & 50 & 1990 \\
\hline 24 & 5750 & 1080 & 4670 & 8960 & 340 & 8620 \\
\hline 72 & 2340 & 3260 & - & 1460 & 1120 & 340 \\
\hline 168 & 2270 & 3610 & - & 930 & 1610 & -- \\
\hline 336 & 1750 & 1820 & -- & 1380 & 1440 & -- \\
\hline 720 & 190 & 230 & - & 650 & 820 & -- \\
\hline 1440 & 320 & 10 & & 360 & 280 & \\
\hline \multirow[t]{2}{*}{2160} & 230 & 0 & & & & \\
\hline & & Cladophora & & \multicolumn{3}{|c|}{ Bladderwort } \\
\hline 4 & & & & 180 & 10 & 170 \\
\hline 8 & & & & 8290 & 60 & 8230 \\
\hline 24 & 96090 & 3140 & 92950 & 7290 & 360 & 6930 \\
\hline 72 & & & & 10810 & 1210 & 9600 \\
\hline 168 & 11910 & 10180 & 1730 & 5540 & 1770 & 3770 \\
\hline 336 & 4720 & 4900 & -- & 1600 & 1670 & -- \\
\hline 720 & 480 & 550 & -- & 1030 & $\log 0$ & -- \\
\hline 1440 & 240 & 10 & & 480 & 480 & \\
\hline 2160 & 410 & 0 & & 160 & 210 & \\
\hline
\end{tabular}

If the equation for rate of change in compartment 1 is expressed as:

$$
\frac{d y}{d t}=c_{1} \lambda(t)-\gamma_{1} y
$$

and either the 24 or 72 hour value is regarded as maximum level reached in the compartment, then 


$$
\frac{d y}{d t}=0 \quad \text { and } \quad c_{1}=\frac{\gamma_{I} y_{\max }}{\lambda(t)}
$$

where $\lambda(t)$ is taken to be the computed value for water at time $t(24$ or 72 hours), and the resulting estimates appear in Table 4.

While we can scarcely claim that the parameter estimates for the first compartment can serve to do more than roughly fill out the curves, It is intriguing that one group of plants seems to have maximum values coincfdent with the peak concentration in water, while several others appear to be definitely delayed in peaking, A very speculative, but nonetheless interesting, notion is that concentration is suspended material might somehow be implicated in the 72-hour peaks, Periphyton uptake should parallel the accumulation of residues in suspended materials and could easily play a major role in the immediate concentration of DDT by some plants, All vegetation samples were rinsed in water but this probably did little more than remove silt and very loose periphyton. Autoradiography would indicate the importance of periphyton residues when gross vegetation samples are assayed,

Figures 5 through 14 show simulation results along with actual data points. The solid line represents the simulated overall concentration (computed in ppb, but plotted in ppm), while the broken line represents concentration in the second (or "slow") compartment, The area between the two lines consequently represents concentration in the first ("fast") compartment, since we computed levels in both compartments as concentrations per unit weight ( $p p b$ or $\mathrm{ppm}$ ) and simply added the two values for totals, it is evident that we are thus implicitly assuming that the two quantities of DDT are in one and the same plant tissue, and 
our "compartments" refer to differences in modes of uptake and retention rather than to separate physical entities. As has already been noted, we followed this route as a matter of necessity rather than choice. Possibly the fast compartment is related to periphyton and plant vascular surfaces while the slow compartment is as sociated with intra-cellular accumulation within the plant.

From inspection of the figures, it seems that the major fault in the simulation is that levels in the first compartment persist too long. In most cases, observed concentrations at either the third or seventh day are substantially below the simulated value. Presumably characteristics of the first compartment might be modified to provide a better fit, but we believe any such change should be based on an investigation of the actual mechanics of DDT uptake and retention by aquatic plants. The essential result of our study seems to be that long-term retention can be fairly well represented by a single component. As a matter of convenience in scaling, most of our graphs extend only to 30 days, but the relation of model and observations at two and three months (1440 and 2160 hours) may be seen in the data of Table 3 ,

The effect of using difference equations to represent differential equations was checked by programing the direct solution of the differential equations (both compartments) and plotting various contrasts between difference and differential equation for two plants (sago pondweed and Cladophora). The principal outcome was that the values for the difference equation, as actually used in this study, exceeded those calculated by direct solution of the differential equation. The discrepancies were usually less than 4 percent, with maximum values of 
about 5 percent at peak concentration. Errors of this magnitude can evidently be neglected for purposes of the present study。

TABLE: 4

Estimates of Compartment Parameters



\section{DDT I N FAUNA}

Studying the faunal components of the system is complicated by the prospect that uptake of DDT may come both from the water and from food. Or initial approach, however, was to determine the results of assuming intake from water alone.

We again assumed two compartments might be implicated, but it turned out that a single compartment might be adequate for several species, Loss rates for the second ("slow") compartment were estimated 
in the same way as for plants, but with the added feature that experimental data were available for loss rates in "clean water" for four species. In August of 1965 (13 months post application) representatives of four species were transferred outside the experimental area, and individuals removed for assay over a 10 to 20 weeks period (Meeks and Peterle, 1967: 152). We can thus contrast loss rates in the two situations, over nearly the same seasonal period. The results (Table 5) provide some assurance that our estimates of loss rates may be realistic.

Transfer rates for the second compartment were obtained in the same manner as for plants, but are, on the average, noticeably higher (Table 4). Basic data are shown in Table 6.

\section{TABLE 5}

Estimates of Loss Rates for Animals, Using Two Methods

\begin{tabular}{|c|c|c|c|c|}
\hline Animal & $\underline{\mathrm{n}}$ & $\underline{\text { LOR-linear }}$ & $\begin{array}{c}\text { Non-linear } \\
\text { Least Squares }\end{array}$ & $s^{2}$ \\
\hline Red leech & 2 & $16.3 \times 10^{-4}$ & -- & \\
\hline Crayfish & 4 & $6.2 \quad "$ & $8.4 \times 10^{-4}$ & .266 \\
\hline Crayff sh* & 5 & 10.5 & $12.8 \quad "$ & .0046 \\
\hline Dragonfly naiad & 3 & 11.2 & 7.6 & .045 \\
\hline Backswimmer & 4 & 40.6 & 28.4 & .035 \\
\hline Bloodworm & 3 & 17.6 & 16.8 & .042 \\
\hline Ramshorn snail & 3 & 6.4 & 32.4 & .039 \\
\hline Carp & 2 & 13.7 & -- & \\
\hline Carp* & 7 & 13.2 & $7.8 \times 10^{-4}$ & .0086 \\
\hline Bullhead & 2 & 7.4 & -- & \\
\hline Bullhead* & 7 & 4.7 & 5.9 & -- \\
\hline Green sunfish & 3 & 2.1 & 2.9 & 2.23 \\
\hline Green sunf ishn & 5 & 5.5 & 5.9 & .011 \\
\hline
\end{tabular}

*in "clean water" 
TABLE 6

Observed Levels in Invertebrates, and Computed Values for Second Compartment

\begin{tabular}{|c|c|c|c|c|c|c|}
\hline \multirow[b]{2}{*}{ Time } & \multicolumn{3}{|c|}{ Crayfish } & \multicolumn{3}{|c|}{ Dragonfly naiad } \\
\hline & 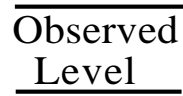 & $\begin{array}{c}\text { Long-term } \\
\text { Compartment }\end{array}$ & Difference & ـ & C & D \\
\hline 4 & 180 & 30 & 150 & 240 & 0 & 240 \\
\hline 8 & 610 & 110 & 500 & 630 & 20 & 610 \\
\hline 24 & 2310 & 670 & 1640 & 1030 & 120 & 910 \\
\hline 72 & 3750 & 2240 & 1510 & 1220 & 410 & 810 \\
\hline 168 & 3550 & 3260 & 290 & 1650 & 620 & 1030 \\
\hline 336 & 2820 & 3010 & - & 590 & 610 & - \\
\hline 720 & 2050 & 1870 & - & 670 & 460 & - \\
\hline 1440 & 590 & 740 & & & & \\
\hline 2160 & 1120 & 300 & & 190 & 150 & \\
\hline
\end{tabular}

Backswimmer

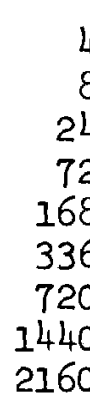

Ramshorn snail

$\begin{array}{rrr}4 & 70 & 10 \\ 8 & 270 & 50 \\ 24 & 1130 & 330 \\ 72 & 770 & 1060 \\ 168 & 990 & 1350 \\ 336 & 900 & 940 \\ 720 & 250 & 280 \\ 1440 & & \\ 2160 & 200 & 0\end{array}$

Bloodworm

\begin{tabular}{rrl}
\multicolumn{3}{c}{ Bloodworm } \\
\hline 890 & 40 & 850 \\
620 & 170 & 450 \\
780 & 1060 & -- \\
2660 & 3510 & -- \\
5200 & 4970 & 230 \\
4150 & 4320 & -- \\
2000 & 2310 & --
\end{tabular}

Red leech

\begin{tabular}{rrr}
\hline & & \\
0 & 0 & -- \\
20 & 90 & -- \\
1740 & 2340 & -- \\
5650 & 8020 & -- \\
6260 & 12430 & -- \\
12630 & 13150 & -- \\
& 11590 & \\
650 & 1110 &
\end{tabular}

For a number of the faunal forms studied, it seems that a "fast" compartment is either not necessary for simulation or relatively small. Thus, for crayfish, it made little difference whether the maximum concentration in the first compartment fell at 24 hours (as was done in the 
simulation for Fig. 15) or at 72 hours (Fig. 16). However, a singlecompartment model did not provide a satisfactory representation for crayfish. Concentrations in both backswimmer (Fig. 17) and bloodworm (Fig. 18) were in conformity with a single-compartment model.

Since several invertebrates had apparent peak concentrations at 7 days post-application, we tried a "fast" compartment with a loss rate selected to peak at about that time (actually between 5 and 6 days), but, as is apparent from the results for dragonfly naiad (Fig. 19), this makes the contribution from the first compartment extend significantly beyond 14 days, and invalidates our method of estimating the transfer rate for the second compartment. Very likely a single-compartment model is to be preferred for the dragonfly naiads.

A two-compartment model for ramshorn snail (Fig. 20) seems to offer little improvement over use of the long-term component alone, The late peak concentration in red leech (Fig. 21) makes fitting a model uncertain, and suggests there may well be reason to implicate a food chain transfer.

In general, however, it appeared that DDT levels in the invertebrates could be approximated rather closely by assuming only uptake from the water. This is by no means sufficient evidence to rule out food-chain transfers, particularly since observations from 12 to 15 months postapplication (Meeks, 1968:384) showed substantial levels in several species, but no detectable levels of DDT in water (this point is investigated below).

The two species of small fish studied (carp and green sunfish) maintained relatively high levels of DD for a full month, so it seems evident that food-chain transfers of DDT were involved. For the carp, 
the more likely food sources were considered to be narrow-leaf pondweed and duckweed. We again assumed two compartments to be necessary, but it did not seem feasible to estimate transfers of DDT from water to the second ("slow") compartment. We thus settled on a "fast" compartment, receiving DD from the water only, and a second compartment with inputs from food only. The first compartment was arbitrarily assumed to have a loss rate of .20 (to give a 24-hour peak) and a transfer rate (equation 8) of:

$$
c_{I}=\frac{\gamma_{2} y_{\max }}{\lambda(t)}=\frac{(.20)(7,580)}{1.53}=991
$$

The second compartment was assumed to have a peak of 10,000 ppb at 2 weeks (although the data showed a lower level then) and an input of $600 \mathrm{ppb}$ at that time from narrowleaf pondweed, giving

$$
c_{2}=\frac{(.00078)(10,000)}{600}=.013
$$

The results (Fig. 22) are remarkably close to observed levels. Using duckweed as food input, but the same transfer rates, gives the results of Fig. 23.

Since small green sunfish (8-10 cm long) were not sampled until one week yost-application, we neglected the first compartment, and assumed the peak concentration at one month came from bloodworms (the only food item of those studied here that might logically be ingested by small sunfish). The transfer rate is 


$$
c_{2}=\frac{(.00059)(5,160)}{2,000}=.00152
$$

The observed values are rather erratic (Fig. 24), and may well represent variable food habits.

It may be noted that the transfer rates are now much smaller than previously encountered, as a consequence of the change to intake materials having much higher levels than those in water. Since these are transfers in terms of parts per unit weight to a unit weight, it would be interesting to speculate on their relation to metabolic requirements. To do so, however, calls for some estimates of time spent feeding, among other things, since the rates are on a per hour basis. The higher rate for carp seems in order, in view of its assumed vegetative diet as opposed to the (presumably) carnivorous sunfish.

The very high initial DDT levels in leopard frog tadpoles (Meeks and Peterle, 1967:117 ) strongly suggested implication of surface contamination, so we constructed a model involving that phenomenon. To do so, we assumed levels at the surface decreased exponentially from the time of application according to the equation

$$
y=A e^{-b t}
$$

$\mathrm{Nb}$ observation was available at the time of application, but it seemed possible the levels then might be reflected by those on duckweed at 4 hours $(17,700 \mathrm{ppb})$. Surface levels at $\mathbf{1}$ hour post-application were $3 \mathrm{ppb}$, so the equation above was approximated as being: 


$$
y=17,700 e^{-.99983 t}
$$

Levels in tadpoles changed from 23.35 ppm at 4 hours to 13.45 ppm at 24 hours, so we estimated a loss rate for a "fast" compartment (fed from the surface contamination) as .028. Input to the first compartment is represented by eq, (3), from which we could compute a transfer rate $\left(c_{I}\right)$ as 1.45 .

For a second compartment, we assume a loss rate of .0036 (from

a change from $6.46 \mathrm{ppm}$ at one week to 3.50 at two weeks). Since tadpoles depend largely on suspended matter for food (but would no doubt also take up DDT directly from water in feeding and respiration) we considered input to the second compartment to come from (unfiltered) water with the maximum level in the second compartment assumed to be at about 7 days, thus:

$$
c_{2}=\frac{(.0036)(6,460)}{1.3}=17.9
$$

These parameters, and the inputs assumed lead to the results of Fig. 25. An alternate approach was to assume the first compartment to contain the observed value (23.35 ppm) at one hour postapplication, and to use the other parameters in tracing events thereafter. Such a model gave results very near to those of Fig. 25.

\section{THE "MATERIAL BALANCE" RROBLEM}

One of the major shortcomings of this study is our inability to trace actual quantities of DDT through the system. Since biomass data 
are largely lacking, we have been forced to work in terms of concentrations, and to employ various rather artificial strategms to estimate the necessary parameters,

Some "total mass" sampling was done (Meeks and Peterle, 1967:147149), by means of sheet-metal cylinders (stovepipes) forced to the bottom of the marsh at 13 different locations (not including stands of emergent vegetation). Only slow-moving animals were caught in the cylinders. Plant and animal components were assayed separately for DDT, as was the upper inch of bottom material. This sampling was done six weeks post-application, when DDT was no longer detectable in the water. Results were expressed as totals per cylinder, as ppm, and as estimates for the entire marsh as follows:

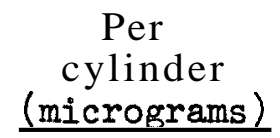

0.14

10.12

200.00
Total

ppm

1.19

2.69

0.30
100.00
$\underline{\operatorname{marsh}(\mathrm{B})}$

0.07

5.06

Sof 1

Thus, about 105 grams of the 360 grams of DDT originally applied could be accounted for after 6 weeks.

An important outcome of this sampling is that the average concentration in plants (2.69 ppm, standard error $=0.91 \mathrm{ppm})$ is considerably higher than that observed in the plant parts sampled at one month (or later) post-application, There is, however, a question about the efficiency 
factor used for the extraction process used for plants in this case, so these particular results may simply be in error.

Surface soil samples (top inch, Meeks and Peterle 1967:71) were taken at 6 weeks, 6 months, and 15 months, and a 11 yielded virtually identical concentrations $(0.30 \mathrm{ppm})$. The constancy of these measurements suggest very little downward movement of DDT, a t least after 6 weeks post-application. The sampling at 15 months did include observations at $15 \mathrm{~m}$ depth $(.007 \mathrm{ppm})$ and $30 \mathrm{~m}$ depth (no detectable residues). Since so much of the DDT is not accounted for, it would be desirable to have data on core samples for an estimate of the total beyond 2.5 am depth. It may well be that downward movement largely occurred in a few days post-application (as the DDT was released from the granules) and that DD became bound to soil materials so that little further movement took place. The nature of such an infiltration process is unknown, but if it is assumed that quantities decrease exponentially with depth, crude calculations from the two observations (surface and $15 \mathrm{~cm}$ ) suggest another 100 grams of DDT might be present below $2.5 \mathrm{~cm}$, leaving on the order of 150 grams unaccounted for (rough guesses as to DDT quantities in emergent plants and biota not represented in the cylinder-samples reduce this to about $130 \mathrm{~g}$ ).

It has already been remarked that no data on release of the DDT from granules are available, and the function used was an arbitrary (albeit reasonable-seeming) one. The differential equation representing concentration in water may be expressed as:

$$
\frac{d y}{d t}+\mu y=\lambda e^{-k t}
$$


where the term on the right is the "input function" or release of DDT from the granules. Our initial assumption was that $\mathrm{k}$ was larger than $\mu$, i.e., that the DDT was released very rapidly (virtually all within 24 hours). That this was a poor choice of assumptions is evidenced by integrating the input function, and introducing our parameter estimates:

$$
\int_{0}^{\infty} \lambda e^{-k t} d t=\frac{\lambda}{k}=\frac{.17}{.08}=2.12 \mathrm{ppb}
$$

Meeks and Peterle (1967:149) estimated that there were about $5 \times 10^{6}$ $\mathrm{kg}$ of water in the area, which implies that only about $10 \mathrm{~g}$ of DDT was released to the water $\left(5 \times 10^{9} \times 2.1 \times 10^{-9}\right)$.

However, behavior of the simulated system is unchanged if we now assume that $\mu$ exceeds $\mathrm{k}$, i.e., that decline in concentration in the water essentially followed decline in rate of release of DDT from the granules. The solution to the above equation is modified only by a change in sign, and our least-squares estimates are also unaffected, beyond the fact that values for $\mu$ and $k$ are interchanged, giving

$$
\begin{aligned}
& \lambda=0.17 \\
& k=0.014 \\
& \mu=0.08
\end{aligned}
$$

Now we have:

$$
\frac{\lambda}{k}=12.14 \mathrm{ppb}
$$


or about $60 \mathrm{~g}$ of DDT released to the water, This still seems a rather small fraction $(1 / 6)$ of the quantity applied, since DDT seems to have been removed from the water relatively rapidly, and built up quickly on plants, it would appear that the immediately adjacent bottom materials might well have directly taken up a very considerable part of the release as it occurred.

Losses from co-distillation would seem to require a fairly rapid process if substantial amounts of DDT were thus lost, The surface concentration of $3 \mathrm{ppb}$ (at one hour post-application) in the top an of water would only amount, to about $1 / 2$ gram of DDT, so does not seem a likely source of a major loss, However, the importance of eo-distillation needs to be determined in field studies,

FOOD CHAIN SIMULATION

DDT levels in the three vertebrates (carp, sunfish, and tadpoles) studied have been assumed to depend, to a considerable extent, on foodchain uptake. We thus have the simple "system" model of Figure 26. Probably the major value of this study lies in demonstrating that simple models do seem to represent the observations fairly well, and in suggesting some of the many aspects that require further study before it can be established whether the model is in fact a realistic one, However, one of the ultimate goals of studying pesticides in food chains should be determining the effeet of repeated applications, or of a continuous input. Such predictions introduce many complications. There is, for example, the matter of seasonal effects, The data used here resulted from an application in early JuIy, and we doubt very much that an 
application in, say, September, would result in the same patterns of uptake and retention, In spite of the unknown, but quite certain, influence of season of application, and the various other untested assumptions of our model, it seems worthwhile to exhibit its behavior under several modes of DDT input. We make no claims that the results are anything like what might happen in practice, but we do think that this kind of modelling has an important place in planning further investigations.

Three kinds of inputs of DDT to the marsh are considered here. One, the single application, has already been described. The other two used for simulation were a continuous input at a constant level, and four applications of the same quantity of DDT at two-weeks intervals. To simulate these regimes, we assembled a computer program with the components of Figure 26, and the parameters deduced above. Three modes of DDT input were provided, with "switch" functions inserted to permit selection of the input desired for a particular compilation of the model.

The first mode is identical to the results presented above, with the exception that the input parameters $\mu$ (removal of DDT from filtered water) and $\mathrm{k}$ (transfer of DDT from granules to water) were reversed so that $\mu=0.08$ and $k=0.014$. As discussed in the section on "material balance," this leaves the model unchanged, but the input function of Figure 1 now becomes as shown in Figure 27.

To simulate a constant input, it is necessary to make an explicit assumption about the actual quantities of DD entering the water, In the section on material balance we calculated a single input as equivalent to: 


$$
\int_{0}^{\infty} \lambda e^{-k t}=\frac{\lambda}{k}=\frac{0.17}{0.014}=12.14 \mathrm{ppb}
$$

so we now assume that a continuous input equivalent to four such single applications will require:

$$
\frac{4(12.14)}{2160}=.0225 \mathrm{ppb} / \text { hour }
$$

over the course of 3 months (2160 hours).

The multiple-input mode assumed the same characteristics as the single input, but incorporated four such input functions spaced two weeks apart; at time zero, 336 hours (mid-July), 672 hours (early August), and 1008 hours (mid-August).

Results of the constant mode of input include the obvious feature that the several levels in water rise to constant levels and remain there-filtered water at about $0.28 \mathrm{ppb}$ (within 2 days), suspended material about $0.57 \mathrm{ppb}$ (after roughly 20 days), and total (unfiltered water), about $0.85 \mathrm{ppb}$ (after 20 days). Concentration in narrow-leaf pondweed was at $1.5 \mathrm{ppm}$ by 10 days and eventually reached $2.0 \mathrm{ppm}$. The first compartment went quickly (within 3 days) to about $1.2 \mathrm{ppm}$, and subsequent change depended on the "slow" compartment, Sinee only one compartment was assumed for bloodworms, levels thus rose slowly, achieving nearly the ultimate maximum of about $6.8 \mathrm{ppm}$ within 2 months. Carp also rose gradually, reaching about 1.4 ppm by conclusion of the run ( 3 months). Tadpoles reached about $4 \mathrm{ppm}$, and sunfish just over $10 \mathrm{ppm}$. Since the inputs are constant, these levels are, of course, fairly easy to calculate directly from the assumed parameters, Tadpoles were assumed to receive 
DDT from water only (no surface contamination).

For the multiple-input mode, subsequent levels in water largely replicate those of the first input, but are slightly higher at peaks due to carry-over from the previous input. Much the same effect shows up in narrow-leaf pondweed, but the final peak is on the order of 7.5 ppm as contrasted with $6.5 \mathrm{ppm}$ in the first peak, and the "trough" level attained about 1.0 ppm after the third peak. Each peak contributed an increment to levels in carp (Figure 28), so that the concentration ultimately exceeded $30 \mathrm{ppm}$, as contrasted to about $10 \mathrm{ppm}$ in the actual experiment with its single "injection" of DDT. Levels in bloodworms show a similar buildup (Figure 29), reaching a peak of about 11 ppm as contrasted to 5 ppm in the experimental application, Sunfish thus go to about 12 ppm (Figure 30), but do so gradually, and smooth out the fluctuations in the source.

While we again caution against literal translation of these results to actual field situations, it does seem that they should serve as a useful example of the interplay of transfer rates and loss rates in the concentration of DDT in passage through a food-chain.

\section{DDT IN THE SECOND SEASON}

Most of the species sampled showed significant levels of DDT in the second season ( 9 to 15 months post-application). Since DDT was not detectable in the water then, there arises the question of source of the observed concentrations. Some of the plants might have retained DDT in storage organs over-winter. The fact that levels in the second season commonly exceeded those at the end of the first season's sampling makes 
such an explanation somewhat awkward. Some species (Cladophora and duckweed) simply have no such unsampled storage site (entire plants were sampled). Hence we are led to consider the prospect that water levels were below detection limits, but nonetheless were largely responsible for the observed concentrations, We thus proceed to use the observed levels on biota to estimate the levels in water necessary to produce such concentrations.

To make much progress, it seems essential to assume a constant DDT level in the water, much as though an equilibrium was established between concentration in water and in bottom materials. Monthly average concentrations in plants (Table 7) roughly support such an assumption, although it seems Likely that the first two months (data are lacking then for many plants) may have had somewhat higher concentrations. At any rate, we assume a constant DDT level in water, and hence equilibrium conditions. We then have

$$
\text { Concentration in biota }(\mathrm{ppb})=\mathrm{y}\left(\frac{\mathrm{c}_{1}}{r_{1}}+\frac{\mathrm{c}_{2}}{r_{2}}\right)
$$

where $\mathrm{y}=$ concentration in water $(\mathrm{ppb})$ and the remaining terms are the compartment parameters of Table 4.

Solving the above equation for y (Table 8) provides estimates of the level in water necessary to produce those observed in plants, The resulting estimates are rather variable, which is not surprising in view of the sizable standard errors attached to many of the loss rate estimates (Table 2) and the aforementioned artificial nature of the first compartment. The average concentration in water calculated from 
TABLE

DDT Concentrations in Plants in the Second Season (ppb)

Curly- Narrow- Soft-

Bur- Sago leaf leaf stem

Water Monthly

Months Cladophora reed Pondweed Pondweed Pondweed Bulrush Duckweed Bladderwort Milfoil Coontail Averages

\begin{tabular}{|c|c|c|c|c|c|c|c|c|c|c|c|}
\hline 9 & 1620 & & & 970 & & & & 530 & 520 & & -- \\
\hline 10 & 320 & & 600 & 480 & & 150 & & 810 & 530 & & -- \\
\hline 11 & 390 & 180 & 460 & 390 & 330 & 70 & 50 & 490 & 200 & 680 & 298 \\
\hline 12 & 660 & 130 & 400 & 180 & 340 & 60 & 30 & 260 & 340 & 730 & 320 \\
\hline 13 & 100 & 10 & 640 & 130 & 240 & 0 & 270 & 180 & 370 & 330 & 212 \\
\hline 14 & & 180 & 990 & 800 & 350 & 90 & 170 & 480 & 400 & 990 & 473 \\
\hline 15 & 400 & 120 & 800 & 310 & & 110 & 80 & & 210 & & 298 \\
\hline
\end{tabular}

$\begin{array}{llllllllll}\text { Average } & 582 & 124 & 648 & 466 & 315 & 96 & 120 & 458 & 367\end{array}$


TABLE 8

Calculations for DDT Levels Expected in Water in Second Season

\begin{tabular}{|c|c|c|c|c|c|c|c|c|c|c|}
\hline & Cladophora & $\begin{array}{l}\text { Bur- } \\
\text { reed }\end{array}$ & $\begin{array}{c}\text { Sago } \\
\text { Pondweed } \\
\end{array}$ & $\begin{array}{c}\text { Curly- } \\
\text { leaf } \\
\text { Pondweed } \\
\end{array}$ & $\begin{array}{l}\text { Narrow- } \\
\text { leaf } \\
\text { Pondweed }\end{array}$ & $\begin{array}{c}\text { Soft- } \\
\text { stem } \\
\text { Bulrush }\end{array}$ & Duckweed & Bladderwort & $\begin{array}{c}\text { Water } \\
\text { Milfoil } \\
\end{array}$ & 1 Coontail \\
\hline$c_{1}$ & 12,140 & 56.8 & 249. & 31.3 & 819 & 44.5 & 610 & 198 & 195 & 1126 \\
\hline$\gamma_{1}$ & .20 & .02 & .20 & .02 & .20 & .02 & .20 & .02 & .20 & .20 \\
\hline$c_{2}$ & 130 & 3.47 & 9.06 & 7.29 & 7.47 & 12.96 & 44.65 & 14.26 & 7.96 & 1345 \\
\hline$\gamma_{2}\left(\begin{array}{ll}\times & \left.10^{4}\right)\end{array}\right.$ & 58.8 & 5.47 & 1.76 & .88 & 25.0 & 39.2 & 55.4 & 11.5 & 7.79 & 151 \\
\hline$c_{1} / \gamma_{1}$ & 60,700 & 2,840 & 1,245 & 1,565 & 4,095 & 2,225 & 3,050 & 9,900 & 975 & 5,630 \\
\hline \multirow[t]{2}{*}{$c_{2} / r_{2}$} & $\underline{22,100}$ & 6,045 & 51,477 & 82,840 & $\underline{2,988}$ & $\underline{3,306}$ & 8,059 & 12,400 & 10,218 & 8,907 \\
\hline & 82,800 & 8,88 & 52,722 & 84,405 & 7,083 & 5,531 & 11,109 & 22,300 & 11,193 & 14,537 \\
\hline
\end{tabular}

Calculated

level in

water $\left(x 10^{3}\right)$

$7.0 \quad 14.0 \quad 12$.

$\begin{array}{llll}5.5 & 44.5 & 17.4 & 10 .\end{array}$

20.5

$32.8 \quad 46.9$ 
plants is .021 ppb, while the few animals for which there is sufficient data (Table 9) give an average of .026 ppb. Clearly such levels are indeed small when compared to those observed in the first few weeks post-application.

It is of some interest to consider the second-season levels in our food chain (Figure 26). Observed concentrations in carp (Table 9) are now too low for food chain intake, which can be calculated as:

$$
\mathrm{y}_{1}\left(\frac{c_{1}}{\gamma_{1}}\right)+y_{2}\left(\frac{c_{\frac{1}{2}}}{Y_{2}}\right)=\text { concentration in } \operatorname{carp}(\mathrm{ppb})
$$

where $y_{1}$ is the level in water $(.02 \mathrm{ppb})$ and $y_{2}$ is that in the assumed food item (narrow-leaf pondweed; 315 ppb in Table 7). The computations give

$$
.02\left(\frac{991}{.20}\right)+315(.00138-100+5250=5350 \text { ppb }
$$

while the observed levels (Table 9) average about $1000 \mathrm{ppb}$, much less than expected. Assuming intake from duckweed yields a calculated concentration in carp of $2100 \mathrm{ppb}$, closer to that observed.

Unfortunately there were no observations on bloodworms in the second season (they were not to be found in appreciable numbers), so calculations for green sunfish become uncertain. Proceeding as though bloodworms were available, we get (both bloodworm and sunfish simulations used single-compartment models):

$$
\text { Concentration in bloodworms }=.02\left(\frac{42.2 z}{.00168}\right)=500 \mathrm{ppb}
$$




\section{TABLE 9}

DDT Concentrations in Animals in the Second Season ( $\mathrm{ppb}$ ) and Levels Expected in Water

\begin{tabular}{|c|c|c|c|c|c|c|c|}
\hline & Red Leech & Crayfish & $\begin{array}{c}\text { Dragonfly } \\
\text { Naiad } \\
\end{array}$ & Backswimmer & $\begin{array}{c}\text { Ramshorn } \\
\text { Snail } \\
\end{array}$ & Carp & Sunfish \\
\hline 9 & & & & & & & 2,230 \\
\hline 10 & & 430 & 140 & & & 2,490 & 1,730 \\
\hline 11 & 1,580 & 760 & 120 & & & 890 & 1,320 \\
\hline 12 & 1,760 & 520 & 200 & 0 & 50 & 730 & 1,490 \\
\hline 13 & 2,000 & 470 & & 150 & 190 & 520 & 1,060 \\
\hline 14 & & 380 & & & & 670 & 1,150 \\
\hline 15 & 2,320 & 270 & & & & 1,140 & 760 \\
\hline Average & 1,915 & 472 & 153 & 75 & 120 & 1,070 & 1,391 \\
\hline$c_{1}$ & 0 & 31.1 & 20.4 & & & & \\
\hline$\gamma_{1}$ & 0 & .02 & .005 & & & & \\
\hline 2 & 76.97 & 26.62 & 4.77 & & & & \\
\hline$\gamma_{2}$ & 16.3 & 12.8 & 7.6 & & & & \\
\hline$c_{1} / r_{1}$ & & 1,555 & 4,080 & & & & \\
\hline$c_{2} / \gamma_{2}$ & $\frac{47,220}{47,220}$ & $\frac{20,796}{22,351}$ & $\frac{6,276}{10,356}$ & & & & \\
\hline
\end{tabular}

Calculated

levol in water $\left(x=0^{3}\right.$ )

21.1

14.8 


$$
\text { Concentration in sunfish }=503\left(\frac{.00152}{.00059}\right)=1300 \mathrm{ppb}
$$

as compared to observed levels in sunfish (Table 9) of about 1400 ppb. Tadpoles were not available in adequate numbers to be sampled in the second year.

While our calculations are obviously subject to several kinds of uncertainty, it does seem that the second season's data are compatible with a very low level of DDT remaining in the water. Under such an hypothesis, it would seem appropriate to add another component to our original input function to allow for a continuing equilibrium between DDT on the bottom and in water.

Samples taken one year later extended the data to 27 months (Meeks and Peterle 1967:209). With the exception of some unreasonably high values for certain plants in two of the five months sampled (some kind of contamination seems probable; one prospect is radioactive fallout from Chinese nuclear testing at about that time), DDT levels in plants were reported as nondetectable. Concentrations in crayfish seemed about as high as those of Table 9, raising the prospect of intakes from bottom detritus, a phenomenon not examined here for lack of relevant data. Carp and sunfish concentrations dropped to roughly $200 \mathrm{ppb}$, or about 1/5 those of Table 9. One might thus assume that any sort of balance between DDT in water and that in sediments steadily declined over the course of two years. 


\section{COMPARISON WITH OIHER STUDIES}

Some further perspective on the problems of modelling pesticides in aquatic systems may be obtained by contrasting the results of this investigation with those of some other studies. To do so, we have used our transfer and loss coefficients to generate rough approximations of concentrations that might be expected in plants and animals on the basis of DDT levels observed in water in a series of published accounts. Two quite different circumstances have to be dealt with, In a few cases, it appears that reasonably constant concentrations of DDT may have prevailed in the water, In other studies, levels of DDT in water resulted from a single, direct application, and diminished very rapidly thereafter.

One "steady-state" situation was hypothesized in the section above on "DDT in the Second Season" in order to account for the reappearance of substantial concentrations in the biota. Very likely this is a prevailing condition in many aquatic systems, but goes largely unstudied by reason of the difficulty of measuring very low levels of" DDT in water. Another possibility for constant levels is in water derived directly from intensive agricultural areas, as irrigation "waste" or "return" water. Keith (1966:7982) has reported on some studies of this sort carried out on four National Wildlife Refuges, One of the refuges (Deer Flat) is left out of consideration in consequence of evidence of a substantial fluctuation in DDT input during the study period. In the other three refuges, concentratrions of DD in filtered water averaged about $0.2 \mathrm{ppb}$ from summer to fall.

Predicting concentrations in the biota for presumed equilibrium conditions depends on the equation: 
conc. in biota $=$ (conc. in water) $\left[\frac{c_{1}}{r_{1}}+\frac{c_{2}}{r_{2}}\right]$

Where the coefficients are those of Table 4, and intake is assumed to come only from water. In effect, this procedure amounts to using a concentration factor.

Since the aquatic vegetation "consisted primarily of pondweeds (Potamogeton spp.)", we have a choice of three possible concentration factors:

Concentration Factor

Sago pondweed

Curly-leaf "

Narrow-leaf "
52,700

84,400

7,080
Prediction (ppm)

10.5

16.9

1.4

The observed values were very nearly 1.0 ppm at all three refuges.

Backswimmers are the only comparable irvertebrates for which we have data, with a concentration factor of 10,500 , giving a prediction of about $2.1 \mathrm{ppm}$, which has to be reduced to 0.5 ppm to change from the dry weight basis of this study to wet weights (Meeks, 1968:202) as apparently used by Keith. Observed values at the three refuges were $0.4,2.5$, and 5.2 ppm. Keith (1966:81) indicated that "Invertebrates ... consisted of various gastropods, crustaceans and insects. Water fleas (Daphnia spp.) and back swimmers (Notonecta spp. and Corfxa spp.) constituted the bulk of most samples."

Keith (1966:81) reported that "At Tule lake and Lower Klamath Refuges, Tui Chub (Siphateles bicolor) were most commonly caught, while at Deer 
Flat and McNary Refuges most samples consisted of Carp (Cyprinus carpio)." Our model for DDT intake by carp assumes a "fast" compartment fed from the water and all other intake from food, giving:

$$
\begin{aligned}
& \text { conc. in carp }=\text { (conc. in water) } \frac{{ }^{c} 1}{r_{1}}+\text { (conc。in food) } \frac{c_{2}}{r_{2}} \\
& \text { with } \frac{{ }_{1}}{r_{1}}=991=4950 \quad \text { and } \frac{c_{2}}{r_{2}}=\frac{.013}{.00078}=16.7
\end{aligned}
$$

Hence if we assume 1 ppm DDT in vegetation, a predicted (dry weight concentration) value for carp is

$$
.0002(4950)+1(16.7)=17.7 \mathrm{ppm}
$$

Reducing this to a wet weight basic yields $4.1 \mathrm{ppm}$ in contrast to $3.3 \mathrm{ppm}$ observed at McNary Refuge (the other two refuges yielded values of 1.5 and 2.5 ppm for Tui chub).

Another study with fairly constant DDT levels in water is that of Godsil and Johnson (1968), also at Tule Lake, These authors report a long series of water analyses that average about .006 ppb (largely DDE). Using our concentration factors, and assuming the reported results to be on a wet weight basis (not specifically stated in the paper), we obtained the following comparison: 
Basis for

$\underline{\text { Reported }} \quad \underline{\text { Prediction }}$

Potamogeton $\mathrm{sp}$.

Cladophora

Tui chub
Sago

Narrow-leaf

Cladophora

Carp $\underline{\text { Predicted }} \quad \underline{\text { Observed (DDE) }}$

$\left.\begin{array}{r}40 \\ 5\end{array}\right]$

1

130

1

50
$5-45$

Our predictions for plants are thus appreciably higher than the observed values. However, we have no basis for Judging what might be expected at such very low levels in the water, so that perhaps the only particularly significant contrast is for the algae, which came out much lower than expected.

A third study of interest is that of Woodwell et al. (1967). The work was done in an estuary, and samples were evidently not taken at regular intervals, and were necessarily rather different species. Comparisons are thus of rather doubtful interpretation. Levels in water were reported as $.05 \mathrm{ppb}$. For the fish samples, we have used as food averages of those items shown in a diagram in a report by Woodwell (1967).

Species

Basis for

$\underline{\text { Reported }}$

Cladophora

Sheepshead minnow

A tlantic

Needlefish

Mud snail $\underline{\text { Prediction }}$

Cladophora

Carp

Green sunfish

Ramshorn snail

Concentration (ppm)

Predicted

1

.3

.1

.1 $\underline{\text { Observed }}$

.08

.9

2.1

.3 
In the three studies discussed above, we have assumed constant DDT levels in water, This is an untenable assumption in most experimental applications of DDT, since the initial concentrations observed in water rapidly diminish and may be below detection limits in a few days. Concentration factors relative to water are then virtually meaningless, For the two such studies to be discussed here, we have assumed an exponential rate of decrease of DDT concentrations in water, and continuous transfer to the biota. Rate of change in one compartment of a particular species is thus assumed to be:

$$
\frac{d y_{i}}{d t}=c_{i} \lambda^{e^{-k t}}-\gamma_{i} y \quad(k>\mu)
$$

giving for the $i^{\text {th }}$ compartment:

$$
\begin{aligned}
& y_{i}(t)=\frac{c_{i} \gamma_{i}}{k-\gamma_{i}}\left[e^{-\gamma_{i} t}-e^{-k t}\right] \\
& k=\text { rate of decrease of DD eoneentration in water } \\
& \gamma=\text { initial DDT concentration in water } \\
& \gamma_{i}=\text { rate of los from the } i^{\text {th }} \text { compartment } \\
& c_{i}=\text { transfer coefficient }
\end{aligned}
$$

We can thus calculate concentration in a particular species on the basis of $c_{i}$ and $\gamma_{i}$ (Table 4). In most instances, sufficient accuracy is obtained by computing results for one compartment--the "fast" compartment in the first few days, or the "slow compartment at or after 14 days, 
In a study by Bridges, Kallman, and Andrews (1963), DDT was applied "to provide an estimated concentration of 0.02 ppm in the water." Initial (surface) concentrations were measured as $80 \mathrm{ppb}$, and dropped to 4 ppb at 8 hours, and $3 \mathrm{ppb}$ at 24 hours, Water samples evidently were not filtered, he have used two estimates of $\mathrm{k}$, one (.37) based on an initial value of $80 \mathrm{ppb}$ and the 8 hour observation, and the other (.09) based on the same initial value and the 24 hour observation. The report gives observational data on sago pondweed as:

$\begin{array}{cc}\frac{\text { Time }}{1 / 2 \mathrm{hr}} & \text { Observed } \\ 8 \mathrm{hrs} & 30.7 \mathrm{ppm} \\ 24 \mathrm{hrs} & 20.6 \\ 1 \mathrm{wk} & 16.9 \\ 2 \mathrm{wks} & 5.9 \\ 3 \mathrm{wks} & 0.9 \\ 4 \mathrm{wks} & 2.6 \\ 5 \mathrm{wks} & 6.0 \\ 6 \mathrm{wks} & 3.7 \\ 7 \mathrm{wks} & 1.7 \\ 8 \mathrm{wks} & 3.0 \\ \end{array}$

Or calculations give values very much lower than those shown above. The maximum we would expect in the fast compartment can be calculated as:

$$
\frac{d y}{d t}=c \lambda e^{-k t}-\mu y=0 \quad Y_{\max }=\frac{c \lambda}{\mu} e^{-k t}
$$


Since $\mathrm{e}^{-\mathrm{kt}}$ is at most unity, $Y_{\max }$ is less than

$$
\frac{250(80)}{.2}=100,000 \mathrm{ppb}
$$

But this value is based on dry weight, and we assume those of Bridges, Kallman, and Andrews are wet weight (although this is not specifically stated in the paper), so an equivalent value (Meeks, 1967:202) is:

$$
100(.12)=12 \mathrm{ppm}
$$

Similar calculations show the slow compartment to have a maximum on the order of 1 ppm or less.

The above study includes data on crayfish showing levels on the order of $1.5 \mathrm{ppm}$ at about one month post-application, Our calculations give predicted values of 0.5 to $2.2 \mathrm{ppm}$, depending on the choice of $\mathrm{k}$ (.37 or .09). A series of samples of rainbow trout were sampled, yielding a maximum of $4.2 \mathrm{ppm}$ at one month post-application, he do not have data to compute comparable estimates, but the time of the maximum is of interest relative to our study, in as much as it suggests ingestion through food rather than uptake from the water as a major contributor to body burden of DDT.

Another study with a rapidly diminishing level of DDT in water is that of Croker and Wilson (1965). The study was conducted in a tidal marsh ditch in Florida, so that environment and biota differ greatly from the freshwater marsh analyzed in this report, Several results 
are nonetheless of considerable interest here. A single application was made, using DDT in acetone in sufficient quantity to produce a rate of 0.2 pound per acre, the same rate as that of the Ohio study. In contrast to the $2 \mathrm{ppb}$ maximum observed in the freshwater marsh, the Florida study reached nearly $50 \mathrm{ppb}$ at one site in 24 hours, then dropped off very rapidly. Very approximate calculations (from data given by Croker and Wilson, 1965) suggest such a concentration in water would require that nearly half of the DDT applied be suspended in the water at that time.

As a crude approximation to DDT input, we assume an exponential decline in the water (following Fig. 3 of Croker and Wilson, 1965:155), starting at $40 \mathrm{ppb}$ at application and decreasing to $5 \mathrm{ppb}$ in 48 hours. A loss rate is then estimated as approximately .04 (per hour). Data on DD levels in the biota are not reported for times earlier than one week post-application, and much of the data pertains to events 3 to 6 weeks, or more, post-application. This means that we can largely ignore "fast" compartments, and drop the term $e^{-k t}$ from eq. (11). For most purposes, the quantity $y_{\mathbf{i}}$ in the denominator can also be ignored, so the equation becomes

$$
Y_{i}(t)=\frac{c_{i} \lambda}{k} e^{-\gamma_{i} t}
$$

Since Cladophora was included in Croker and Wilson's (1965:156, legend of Fig. 4) vegetation samples, we calculate an expected value at 1 week as: 


$$
\frac{130(40)}{.04} \mathrm{e}^{-.0059(168)}=48 \mathrm{ppm}
$$

Whereas the observed value was on the order of 5 ppm (dry wt.) at that time. Howeves, at one site levels in vegetation then rose to a peak of $70 \mathrm{ppm}$ at 4 weelss post-application. This, along with erratic behavior of DDT concentrations in sediments and vegetation samples at other sites, suggests that DDI must have keen somehow remobilized some 4 to 6 weeks after the initial application.

Two samples of snails (Neritina reclivata) were collected at 6 weeks after treatment, and yielded 2.5 and 11.2 ppm for two different locations. Using our data for ramshorn snails (Planorbidae) we calculate 6 weeks values as:

$$
\frac{13(40)}{.014} e^{-.0052(503)}=2 \mathrm{nom}
$$

but this is dry veight and would be reduced a factor of 0.2 to 0.6 for wet weight, depending on metier only soft parts or the entire snail was used for DCT analysis.

A series of DDT determinations on various species of fish ranged from 2 to $90 \mathrm{ppm}$ (wet it.). Assuming concentrations on vegetation at 5 and 1.0 ppm (equilibrium levels), our concentration factor of 17 for carp gives predictions on the order of 20-40 ppm. 


\section{DISCUSSION}

In the introduction to this paper, we indicated two objectives for the study, The first was to investigate the applicability of methods used for modelling radionuclide transfers in food chains to similar studies of pesticides, The outcome of the study suggests that simple compartment models do seem to represent data on the behavior of DDT in a freshwater marsh reasonably well. The second objective, defining areas for further study, may be conveniently discussed in two categories,

The first category might be called "system identification," and is one requiring much experimental work. We have assumed many of the items of the bfota to effectively contain two compartments, but without any real knowledge of the nature of such compartments. There is an evident need for controlled experimentation to identify major compartments in individual organisms, and to measure uptake and retention rates. There is also an obvious need for definitive data on the relative importance of direct uptake of DDT from water versus uptake through food chains, or, in the case of plants, transfer by suspended matter or contamination through uptake by periphyton. Mechanisms controlling release of DDT from granules and other media need definition, as do the forces controlling its distribution -- diffusion, currents, and so on,

The second category has to do with the design of a particular study, and might be described as "the sampling problem". Samplings in both time and space are necessarily involved. Sampling in time might conveniently be associated with curve-fitting problems -- for a given organism or substance, what is the best pattern of sampling over time? Since one clearly cannot hope to obtain enough samples to adequately define the 
multitude of relevant features of any natural system, some sort of compromise scheme has to be adopted to meet the requirements of sampling over time and those associated with spatial coverage. As a starting point, allocation over time might be dealt with in terms of the pattern and number of samples necessary to describe a particular curve reasonably well.

Sampling in space is perhaps not a broad enough term, since the real need is for sampling the "system". In addition to coordinates of time and space, one must also deal with components of the biota and substrate. Choice of a species list for sampling may perhaps best be predicated on the objectives of the study. In some cases, concern with hazards to man or to certain economically or ecologically important species may lead to the selection of a reduced list of key species. Justifying a given list may, however, require a much better knowledge of ecosystem dynamics than we now have.

Fop exploratory studies, like the one analyzed here, a preferred objective may be what we have called a "balance study". The ultimate goal may then be described as one of determining the fate of all of the DDT released in the study. Since DDT is already so widely distributed, this immediately puts a further premium on the use of a radioactive label. Obviously considerable prior knowledge of the system is necessary for planning. It will not only be necessary to estimate the biomass of components of the system, but also to decide in advance what components will contain the main quantities of DDT (or other contaminant) at various points in time. Physical features of the study area, along with variation in the application method, will certainly lead to spatial 
variability in concentrations in a given species, Differences in size and physiological state will very likely also contribute to variability between individuals.

"Pooling" samples is one frequently-used method for reducing the sampling load, This technique may serve to meet the objectives of a balance study, in the sense of determining the ultimate fate of the initial quantity of DDT, but the differences between species encountered in the present study indicate that pooling villz obscure the dynamics of the system, Very likely only a great deal more experience with sampling individual components wiIl serve to determine when pooling is desirable.

As experience and background data accumulate, simulation modelling w ill become an increasingly useful tool in designing and conducting system studies. A reasonably good model should permit rapid testing and revision of sampling schemes. In the face of uncertainty about various components of the system, the experimenter may elect to test alternate study schemes against very different patterns of system behavior, and can thus obtain some notion of the "sensitivity" of various methods to deviations from the expected pattern of events. As an example, in the present study we have not assumed any recycling of DDT. That is, we assumed DDT was released either to the biota or to bottom sediments. Losses from the biota were assumed to be taken out of cfrculation, so to speak. An alternative that might readily be studied on a computer is to assume such losses were returned to the water and potentially recycled. Further, results from the second year of the study suggest some sort of equilibrium concentration in water, and presumably such a circumstance would depend on return from 
bottom materials. A simulation study might be very helpful in planning specific experiments to study these unresolved questions of routes and mechanisms.

It seems likely that real success in understanding both the dynamics of ecosystems, and the behavior of contaminants in ecosystems will depend on construction of rather sophisticated models of a sizable number of systems for detailed comparative studies. The present study suggests something of the prospects and of the shortcomings in the available data and methods. We believe that a great deal of progress is possible with presently available techniques, but conclude this reort by noting that we have not touched at a 11 on one of the primary problems -- that of effects of DDT on the ecosystem. 
IITERATURT CITED

Bridges, W. R., B. J. Kallman, and A. K. Andrews. 1963. Persistence DD and its metabolites in a farm pond. Trans. Am. Fish. Soc. $92: 421-427$.

Croker, R. A. and A, J. Wilson. 1965. Kinetics and effects of DD in a tidal marsh ditch. Trans. Am. Fish. Soc。 94:152-159.

Eberhardt, L. L. and W. C. Hanson. 1969. A simulation model for an artic food chain. Health Physics 17:793-806.

Godsil, P. J. and W. C. Johnson. 1968. Pesticide monitoring of the aquatic biota at the Tule Lake National Wildlife Refuge. Pesticides Monitoring J. I(4):21-26.

Keith, James 0. 1966. Insecticide contaminations in wetland habitats and their effects on fish-eating birds, J. Appl. Ecol. 3. (Suppl.): $71-85$.

Meeks, R. L. and T. J. Peterle. 1967. 'L'he cycling of $\mathrm{Cl}^{36}$ labeled DDT in marsh ecosystem. Report No. CDD-1358-3, The Ohio State University Research Foundation, Columbus, Ohio. 220 pp.

Meeks, R. L. 1968. The accumulation of $\mathrm{Cl}^{36}$ ring-labeled DDT in a freshwater marsh. Journ. Wildl. Mgmt. 32(2):376-398.

Pugh, A. L. 1963. "DYNAMO user's manual." Second Edition. M.I.T. Press, Cambridge, Massachusetts.

Woodwell, G. M., C. F. Wurster, Jr., and P. A. Isaacson. 1967. DDT residues in an East Coast estuary: a case of biological concentration of a persistent insecticide. Science 156:821-824.

Woodwell, G. M. 1967. Toxic substances and ecological cycles. Scientific American 216(3):24-31. 

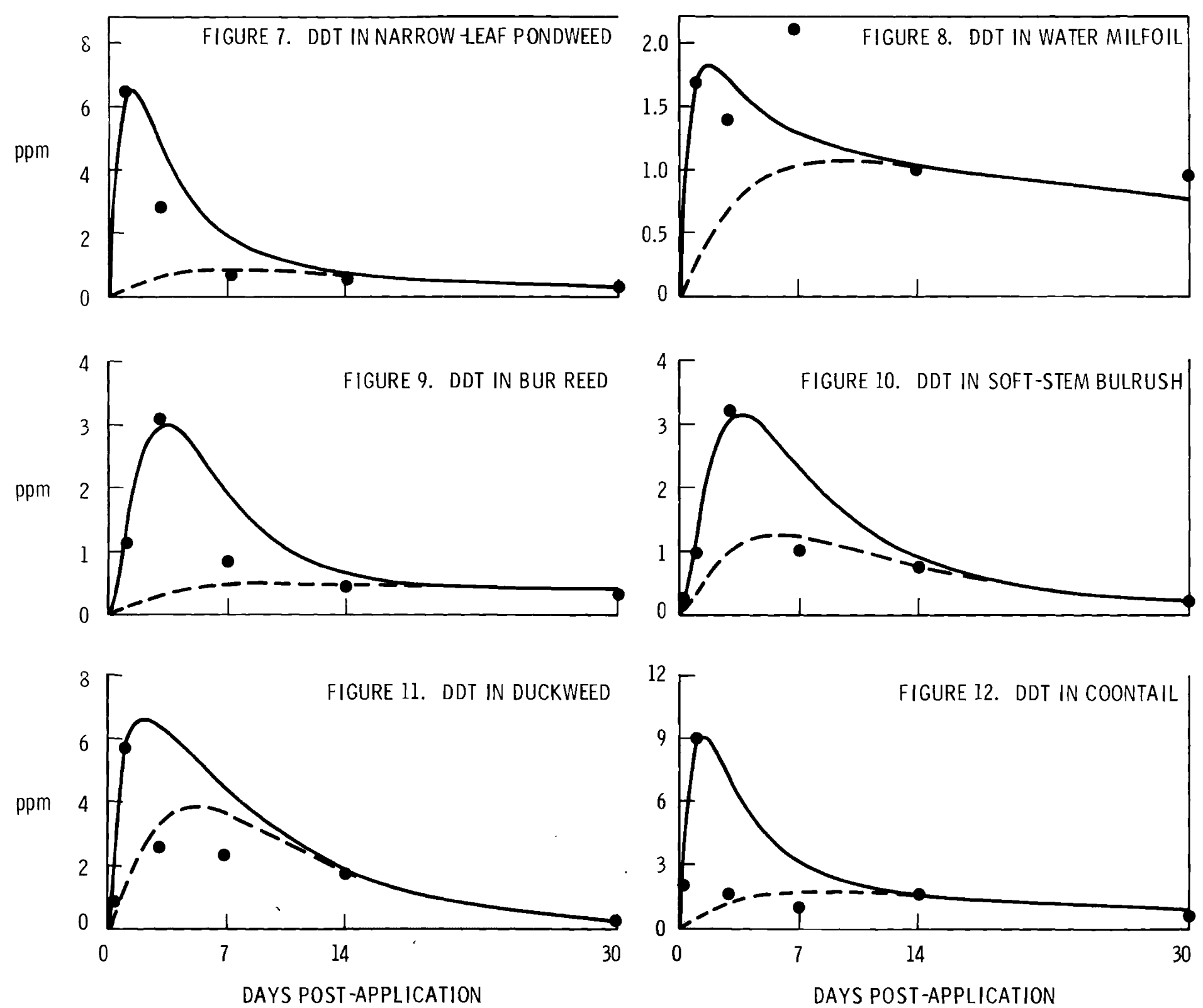

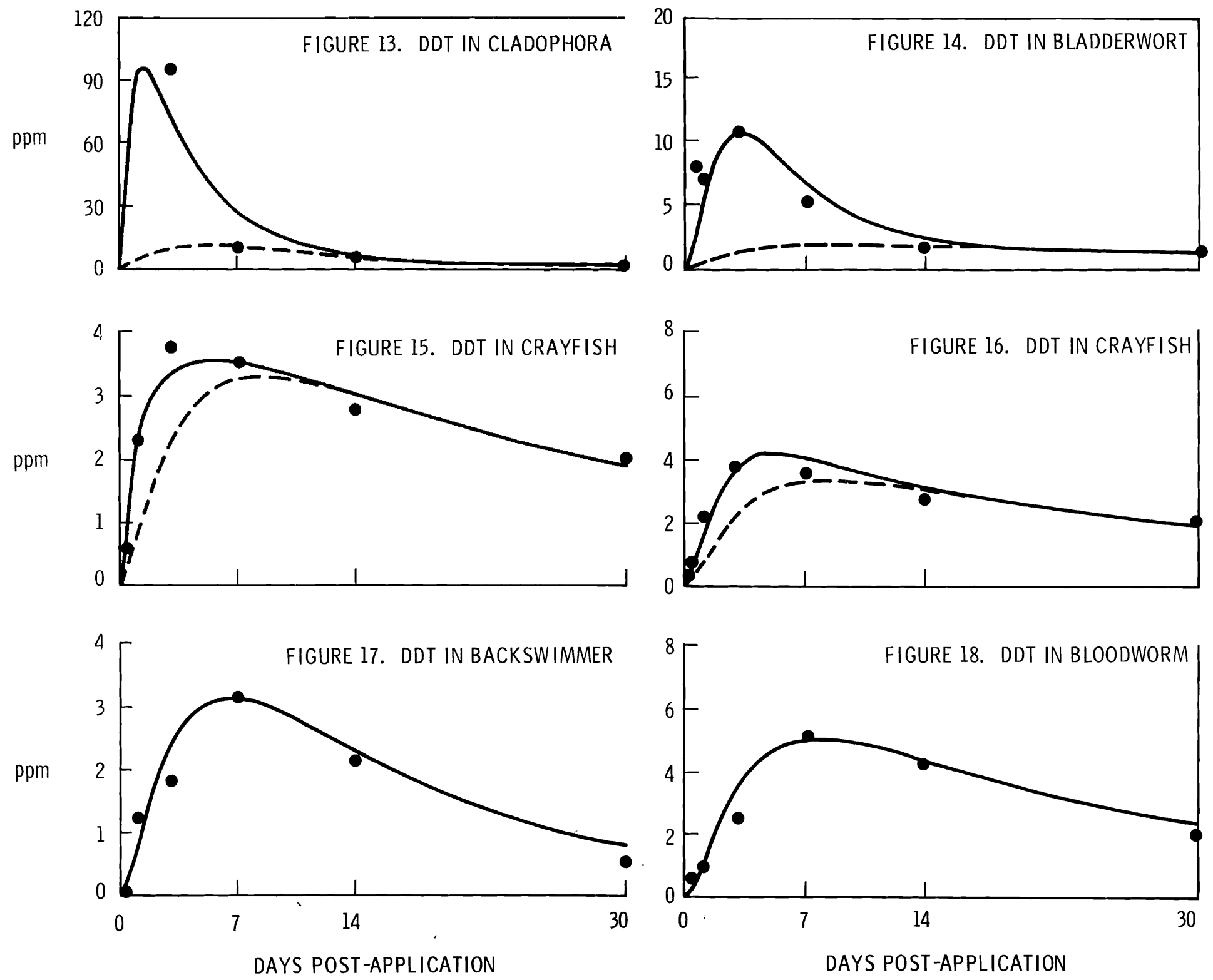

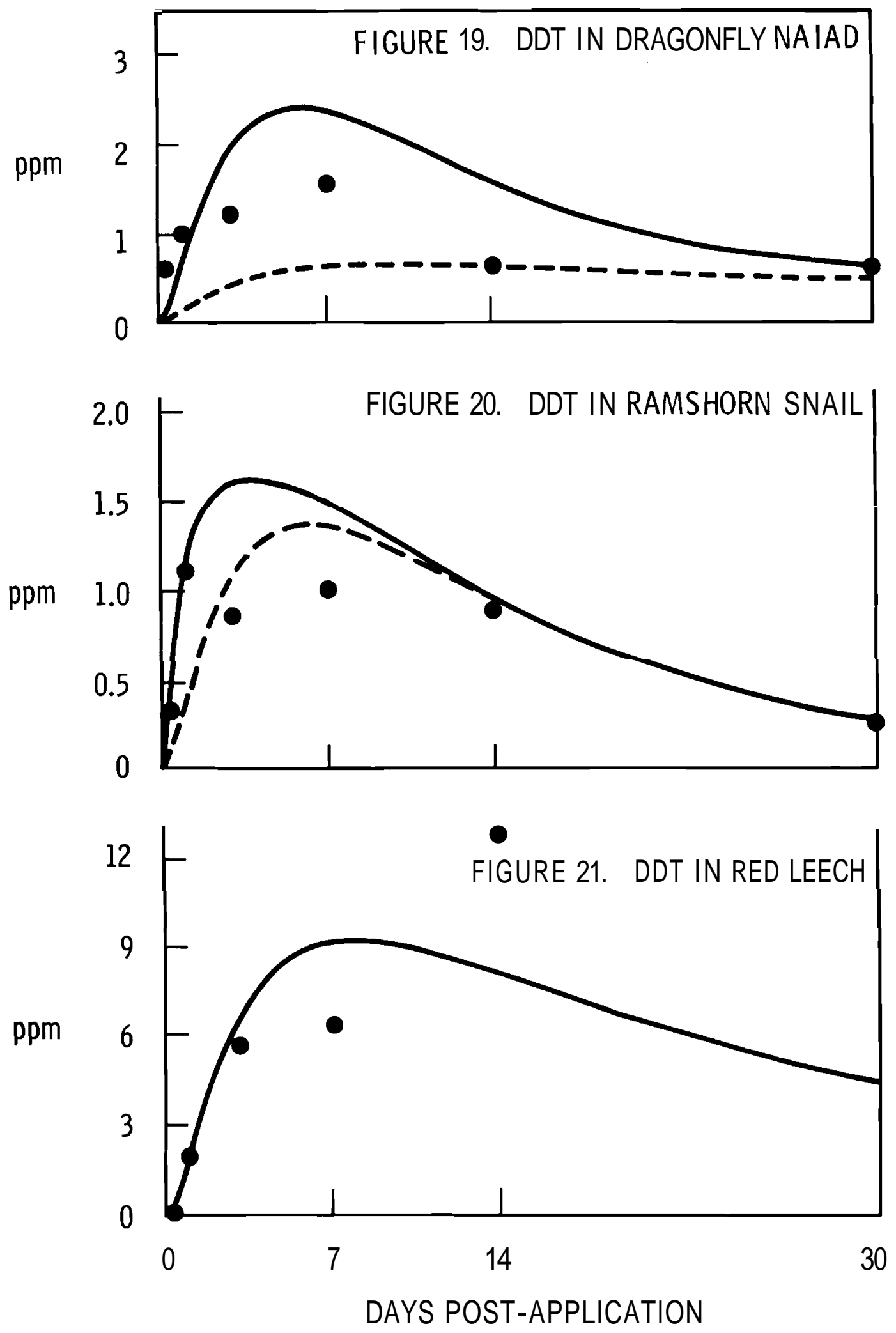

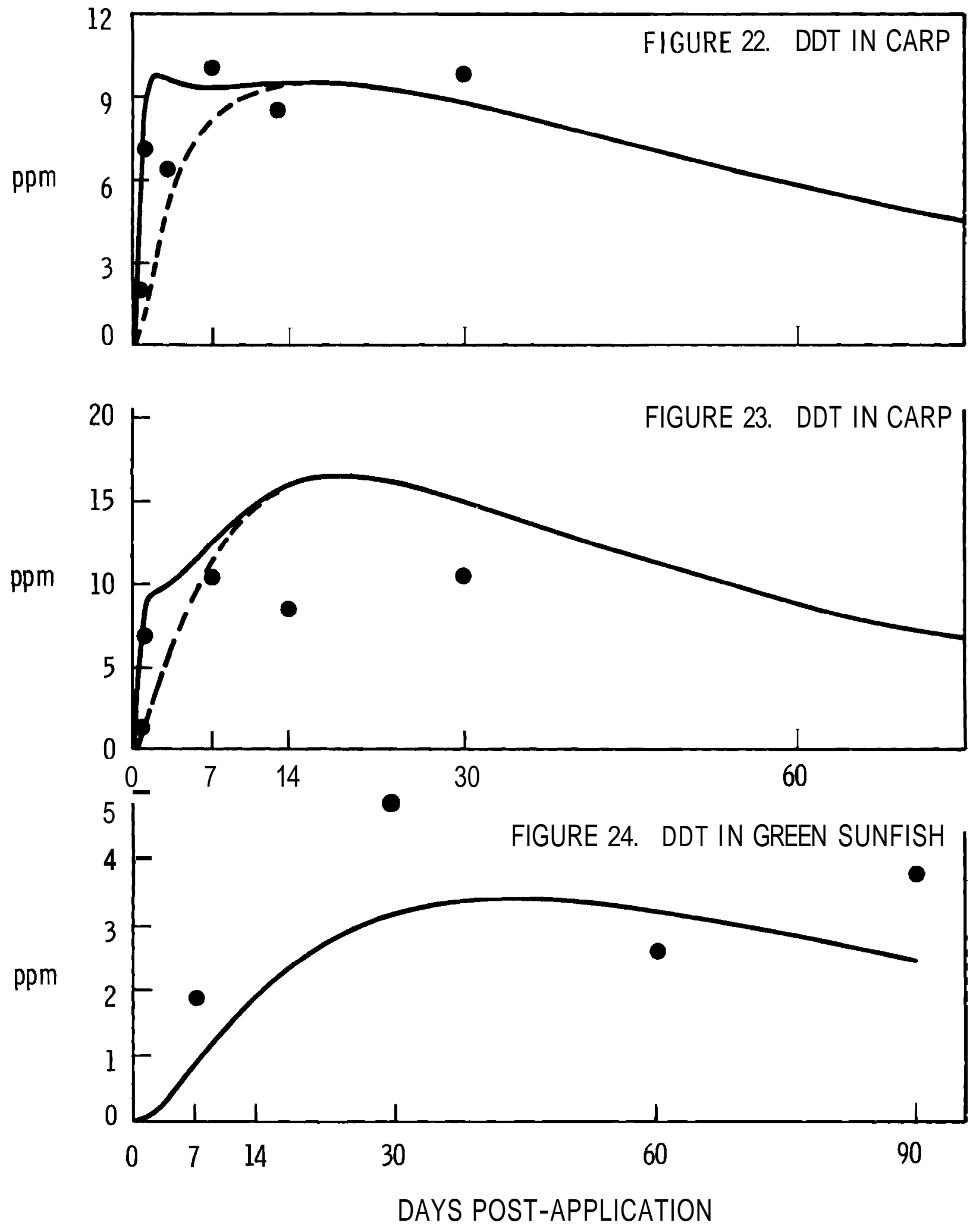

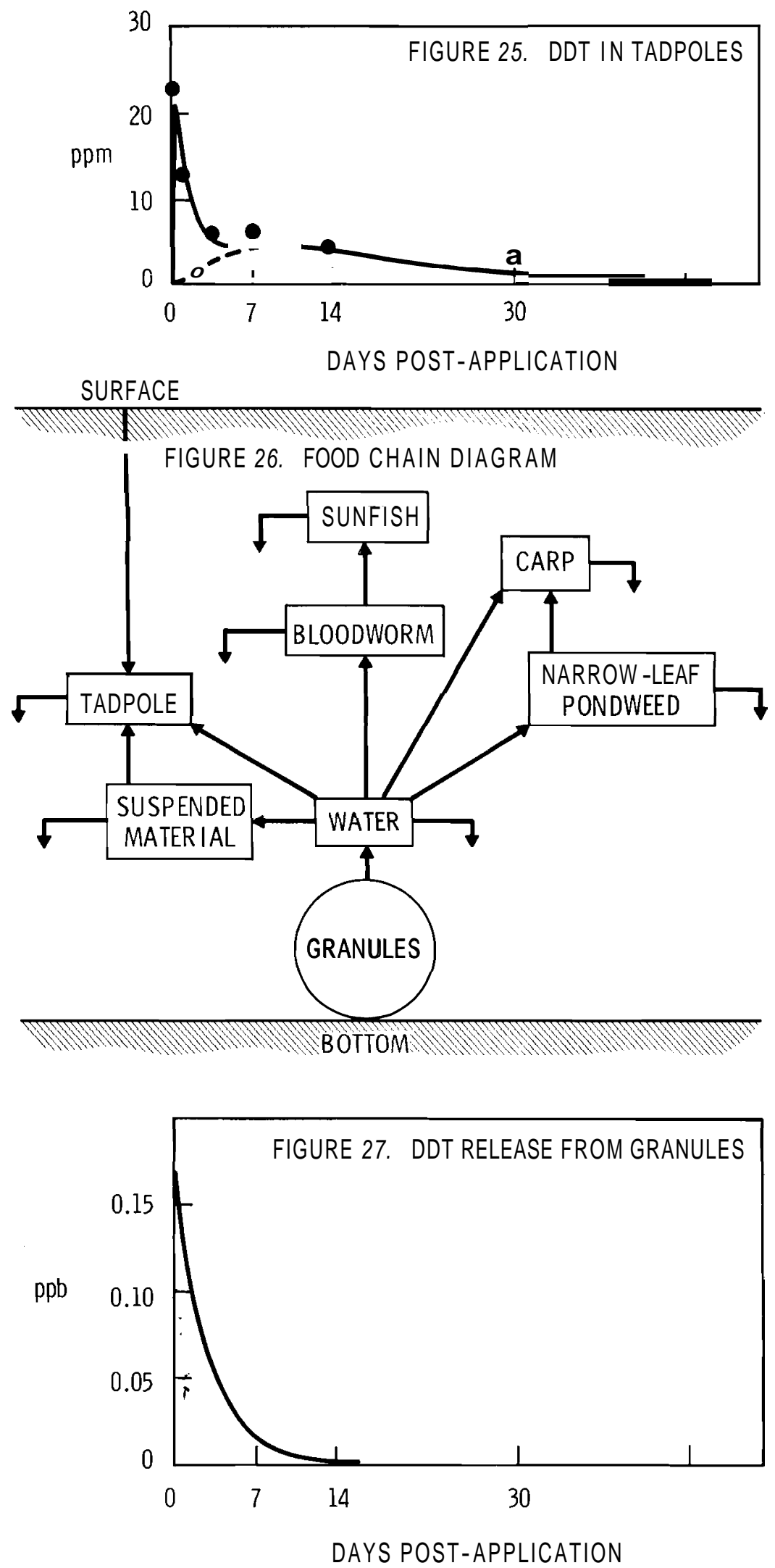

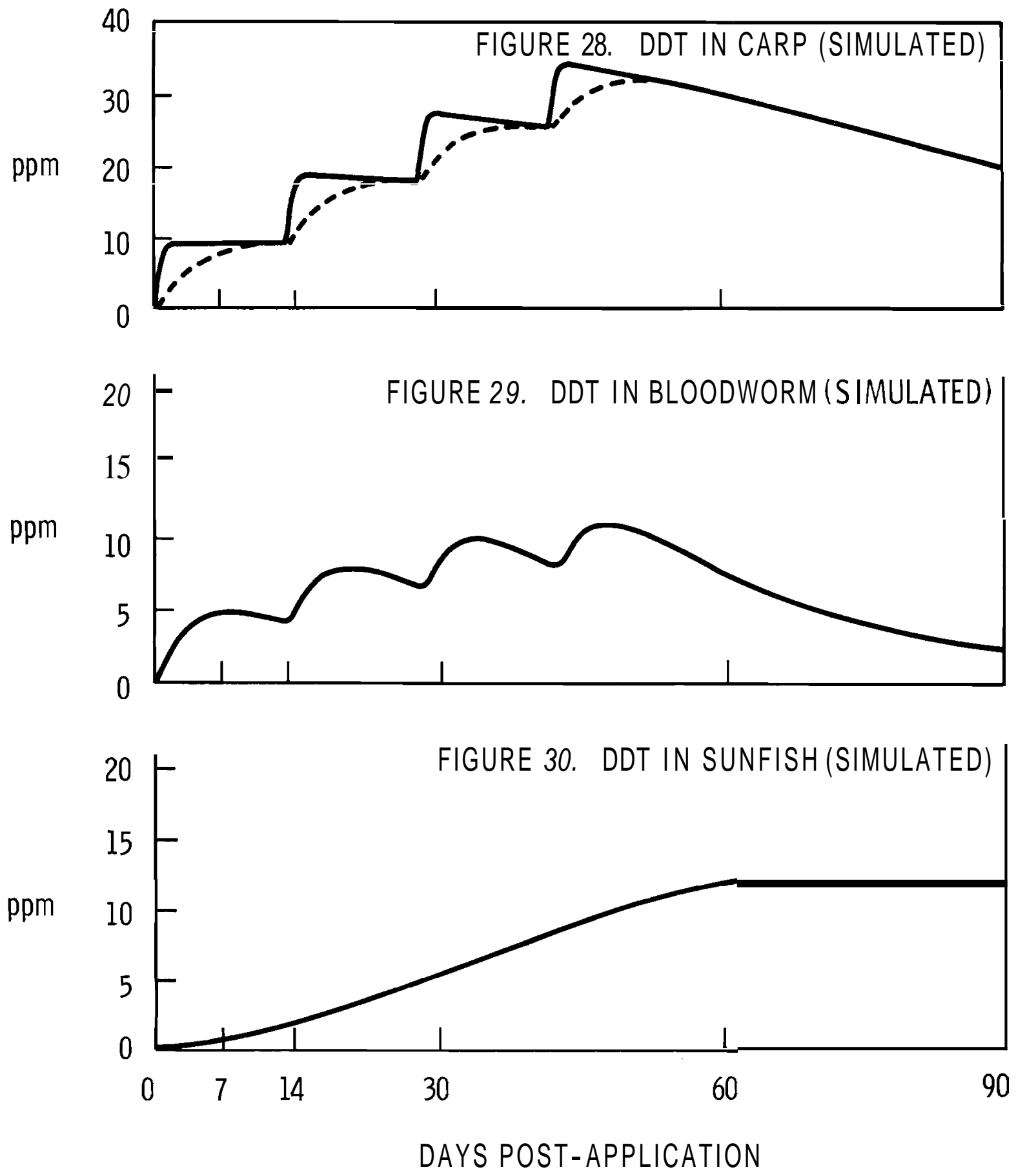


\section{DISTRIBUTION}

No. of

Copies

OFFSITE

1

AEC, Chicago Patent Group

G. H. Lee

$111 \quad \underline{A E C, D T I E}$

For UC-48 Distribution

\section{OFFSITE}

7

AEC, Division of Biology and Medicine

5 C. L. Osterberg

2 H. L. Hollister

\section{ONSITE - HANFORD}

1 AEC, Chicago Patent Group

R. K. Sharp

2

$\mathrm{AEC}, \mathrm{RL}$

1 C. L. Robinson

2 M. W. Tiernan

2

AEC, RDT Site Representative

P. G. Holsted

3 Battelle Memorial Institute

$171 \quad$ Battelle-Northwest

5 Technical Information

2 Technical Publications

1 W. J. Bair

1 R. F. Foster

1 R. E. Nakatani

5 T. P. O'Farrell

1 K. R. Price

5 W. L. Templeton

150 L. I. Eberhardt 